\title{
Critical assessment of the current state of scientific knowledge, terminology, and research needs concerning the role of organic aerosols in the atmosphere, climate, and global change
}

\author{
S. Fuzzi ${ }^{1}$, M. O. Andreae ${ }^{2}$, B. J. Huebert ${ }^{3}$, M. Kulmala ${ }^{4}$, T. C. Bond ${ }^{5}$, M. Boy ${ }^{4}$, S. J. Doherty ${ }^{6}$, A. Guenther ${ }^{7}$, \\ M. Kanakidou ${ }^{8}$, K. Kawamura ${ }^{9}$, V.-M. Kerminen ${ }^{10}$, U. Lohmann ${ }^{11}$, L. M. Russell ${ }^{12}$, and U. Pöschl ${ }^{2,13}$ \\ ${ }^{1}$ Istituto di Scienze dell'Atmosfera e del Clima, Consiglio Nazionale delle Ricerche, 40129 Bologna, Italy \\ ${ }^{2}$ Biogeochemistry Department, Max Planck Institute for Chemistry, 55128 Mainz, Germany \\ ${ }^{3}$ Department of Oceanography, University of Hawaii, Honolulu, HI 96822, USA \\ ${ }^{4}$ Department of Physical Sciences, University of Helsinki, 00014 Helsinki, Finland \\ ${ }^{5}$ Department of Civil and Environmental Engineering, University of Illinois, Urbana, IL 61801, USA \\ ${ }^{6}$ IGAC Core Project Office, Seattle, WA 98115, USA \\ ${ }^{7}$ Atmospheric Chemistry Division, National Center for Atmospheric Research, Boulder, CO 80307-3000, USA \\ ${ }^{8}$ Environmental Chemical Processes Laboratory, Department of Chemistry, University of Crete, 71409 Heraklion, Greece \\ ${ }^{9}$ Institute of Low Temperature Science, Hokkaido University, Sapporo, Hokkaido 060-0819, Japan \\ ${ }^{10}$ Finnish Meteorological Institute, 00810 Helsinki, Finland \\ ${ }^{11} \mathrm{ETH}$, Institute for Atmospheric and Climate Science, 8093 Zurich, Switzerland \\ ${ }^{12}$ Scripps Institution of Oceanography, University of California, La Jolla, CA 92093-0221, USA \\ ${ }^{13}$ Institute of Hydrochemistry, Technical University of Munich, 81377 Munich, Germany
}

Received: 29 September 2005 - Published in Atmos. Chem. Phys. Discuss.: 16 November 2005

Revised: 23 March 2006 - Accepted: 21 April 2006 - Published: 9 June 2006

\begin{abstract}
In spite of impressive advances in recent years, our present understanding of organic aerosol (OA) composition, physical and chemical properties, sources and transformation characteristics is still rather limited, and their environmental effects remain highly uncertain. This paper discusses and prioritizes issues related to organic aerosols and their effects on atmospheric processes and climate, providing a basis for future activities in the field. Four main topical areas are addressed: i) sources of OA; ii) formation transformation and removal of OA; iii) physical, chemical and mixing state of OA; iv) atmospheric modelling of OA. Key questions and research priorities regarding these four areas are synthesized in this paper, and outstanding issues for future research are presented for each topical area. In addition, an effort is made to formulate a basic set of consistent and universally applicable terms and definitions for coherent description of atmospheric OA across different scales and disciplines.
\end{abstract}

Correspondence to: S. Fuzzi

(s.fuzzi@isac.cnr.it)

\section{Introduction}

Organic aerosol (OA) components account for a large, sometimes even dominant, fraction of air particulate matter. They influence the physical and chemical properties of aerosol particles and thus have effects on the atmosphere and climate through interaction with reactive trace gases, water vapour, clouds, precipitation, and radiation. Moreover, they influence the biosphere and human health through the spread of reproductive materials and micro-organisms, impacts on respiratory and cardiovascular functions, as well as allergic and infectious diseases (Fig. 1). At present our understanding of OA composition, physical and chemical properties, sources, transformation and removal characteristics is very limited, and estimates of their actual environmental effects are highly uncertain. Figure 2 illustrates the interdependencies between aerosol sources and formation, composition and properties, interactions and transformation, and climate and health. Obviously, the resulting feedback loops are of central importance for the science and policy of environmental pollution and global change. Thus a comprehensive characterization (climatology) and mechanistic understanding of particle sources, properties, and transformation is required for quantitative assessment, reliable prediction, and efficient

Published by Copernicus GmbH on behalf of the European Geosciences Union. 

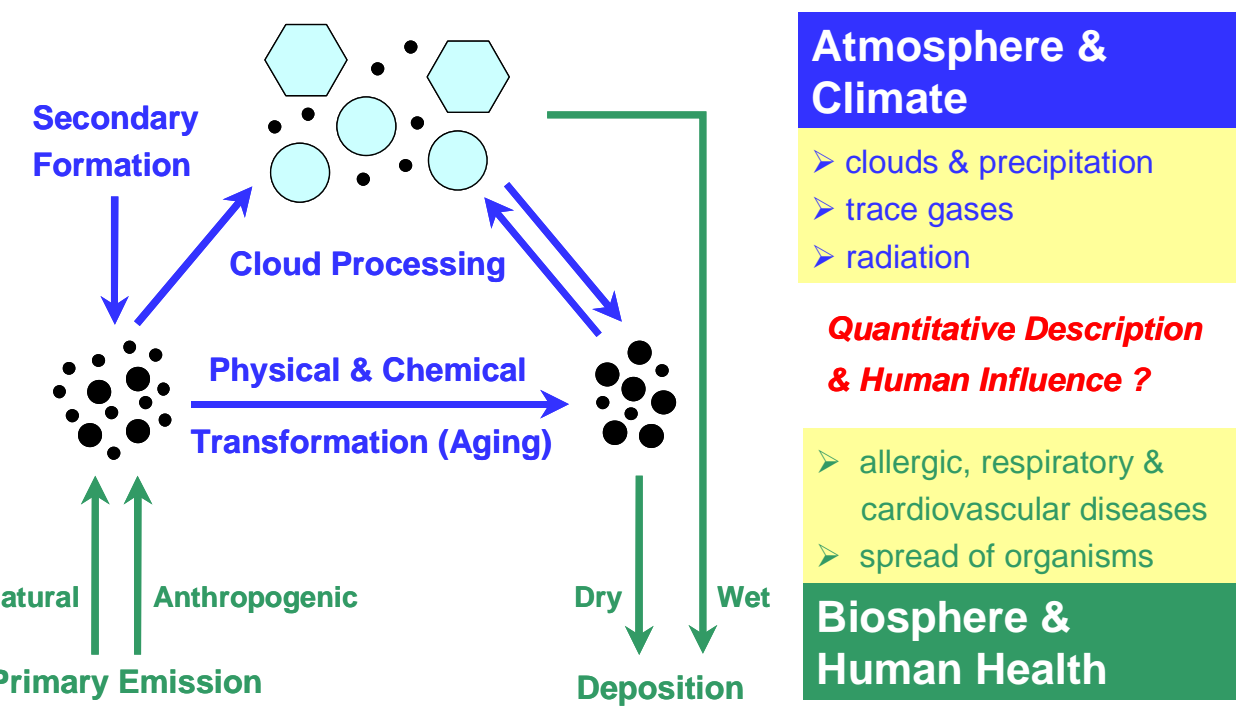

Fig. 1. Atmospheric cycling of organic aerosols and effects on the climate system and human health (Pöschl, 2005).

control of natural and anthropogenic aerosol effects on climate and public health.

Several scientific papers have reviewed our understanding of OA occurrence and behaviour in the atmosphere (Jacobson et al., 2000; Turpin et al., 2000; Seinfeld and Pankow, 2003; Kanakidou et al., 2005). The present paper, resulting from a topical international workshop discussion (see acknowledgement section for details) is not aimed at providing a comprehensive literature review on the issue, as for example the paper by Kanakidou et al. (2005), but instead wants to be problem-oriented and forward-looking, addressing more conceptual aspects, as e.g. the issue of common terminology, and prioritizing issues connected to OA and their effects on the environment and climate, providing the basis for future international collaborative efforts on this extremely complex subject. Reduction of uncertainties will require a comprehensive characterization and investigation of OA by laboratory and environmental chamber experiments, field measurements, remote sensing, and modelling studies. These studies, to be effective, require efficient planning, coordination, and exchange of results within the international scientific community.

\section{Terminology}

In the current scientific literature and discussion of atmospheric aerosol properties, interactions, and effects, the terminologies of different studies and communities are not always consistent. For example, the attributes "primary" and "secondary" have been used with a range of different meanings for aerosol particles and their chemical components, depending on the scientific approach, techniques, and focus.
The use of inconsistent terms can easily lead to misunderstandings and confusion in the communication between specialists from different (sub-)disciplines of atmospheric and climate research, and may thus potentially inhibit scientific progress. Here we attempt to compile and clarify a set of consistent and universally applicable basic terms for the investigation, characterisation, and modelling of the sources, formation and transformation, properties, and effects of $\mathrm{OA}$ in the atmosphere.

The proposed definitions are largely consistent with the basic terminologies defined in earlier studies and monographs of atmospheric aerosol research (e.g., the Glossary of the 2001 IPCC Report; IPCC, 2001). They are, however, more explicit, detailed, and comprehensive with respect to $\mathrm{OA}$ and their chemical components.

\subsection{Aerosol particles and gas phase}

In general, aerosols are defined as colloidal systems of liquid or solid particles suspended in a gas. Thus, in principle, the term "aerosol" comprises both the aerosol particles and the gas phase, in which the particles are suspended, and the term "aerosol component" may refer to any particulate or gaseous substance in the colloidal system. In atmospheric research, however, the terms "aerosol" and "aerosol component" usually refer to the particles (condensed phase). Only when gas-particle interactions are considered (new particle formation; gas-particle partitioning; heterogeneous or multiphase chemical reactions), it is customary to explicitly distinguish between "particle components" ("particulate components", "condensed phase components") and "gas phase components". 


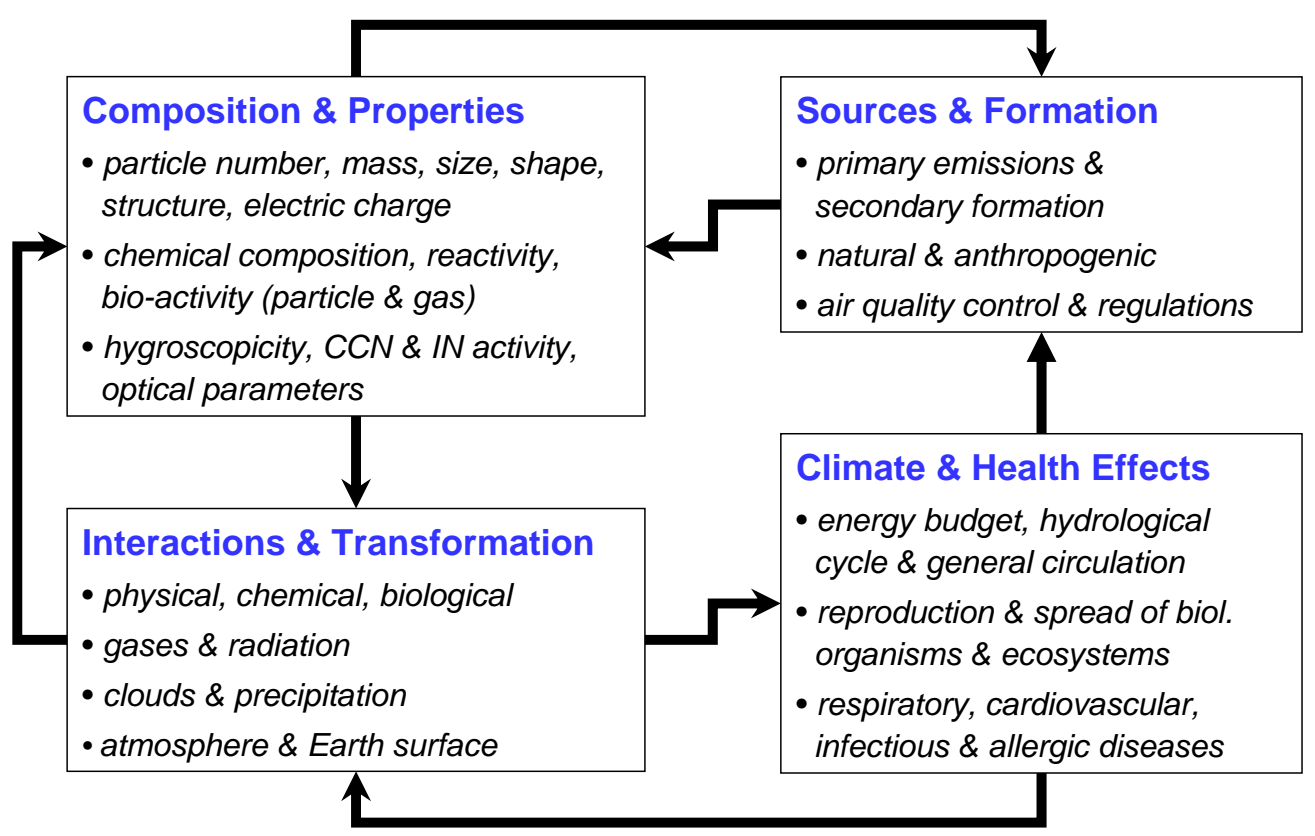

Fig. 2. Interdependencies and feedback loops between atmospheric aerosol sources and formation, composition and properties, interactions and transformation, and climate and health effects (Pöschl, 2005).

2.2 Volatile, semi-volatile, and non-volatile aerosol components

Volatile components of atmospheric aerosols are not condensable under actual atmospheric conditions and reside in or on the condensed phase only to the extent to which they can be absorbed (dissolved) in the particle bulk or adsorbed on the particle surface. Semi-volatile components are condensable and can reside largely in the condensed phase or in the gas phase, depending on atmospheric conditions. Lowvolatility and non-volatile components reside almost exclusively in the condensed phase.

\subsection{Primary, secondary, and aged aerosol particles}

Primary particles of atmospheric aerosols are formed within a source and directly emitted to the atmosphere, whereas secondary particles are formed in the atmosphere by condensation (nucleation and growth) of gaseous precursors. This definition and discrimination of primary and secondary aerosol particles is meant to be fully compatible with and flexibly applicable for different approaches of scientific investigation and mathematical modelling of atmospheric aerosols at all scales (molecular processes to global atmosphere):

1. detailed process studies (laboratory and field experiments; chemical and microphysical box models): source $=$ leaf/tree, engine/factory tailpipe, etc.; particles formed in a forest canopy or cooling exhaust plume considered as secondary (formed outside the source);
2. simplified large scale studies (regional or global atmosphere and climate models): source $=$ forest/ecosystem, urban area, etc.; particles formed in a vegetation canopy or street canyon considered as primary (formed inside the source).

The formation of particles in emission or exhaust plumes outside a point source or source region (industrial and vehicle tailpipe; forest canopy, etc.) generally depends on ambient temperature, radiation, and atmospheric composition (water vapour, other co-condensable vapours/gases, photo-oxidants, etc.). Thus identical emissions from identical sources (aircraft, ships, vehicles, ecosystems, plants, animals, soil, micro-organisms, etc.) can and will produce different amounts of particles under different conditions (day/night; summer/winter, tropical/polar). In accordance with the definitions outlined above, this can be explicitly resolved in detailed process models or included in the emission parameterisations of simplified large-scale models. Aged particles have undergone physical or chemical transformation in the atmosphere (coagulation; structural rearrangement; phase transition; growth/shrinkage by condensation/evaporation of semi-volatile components; adsorption/absorption of volatile components; chemical transformation). Obviously, both primary and secondary particles can undergo atmospheric aging.

\subsection{Primary and secondary aerosol components}

Primary chemical components of atmospheric aerosols are substances formed within a source and directly emitted into 
the atmosphere, whereas secondary chemical components are substances formed by chemical reactions in the atmosphere. Secondary components can be formed in the gas phase and condense onto pre-existing particles or lead to the formation of new particles, but they can also be formed by chemical transformation of primary components in the condensed phase. Moreover, chemical aging (transformation) of atmospheric aerosols can lead to the formation of multiple generations of secondary chemical components. Note that aged primary aerosol particles can contain secondary chemical components (e.g., transformation of primary non-volatile components or uptake of secondary semi-volatile components) and secondary aerosol particles can contain primary chemical components (e.g., contribution of primary semivolatile components to the nucleation and growth of secondary particles).

2.5 Organic, inorganic, and carbonaceous aerosols (particles)

In organic, inorganic, and carbonaceous atmospheric aerosols (particles), the chemical composition and physicochemical properties of the condensed phase are dominated by organic, inorganic, or carbonaceous components (organic compounds and black/elemental carbon), respectively.

Typically, aged atmospheric aerosol particles contain both organic and inorganic components which influence their physico-chemical properties and atmospheric effects. Nevertheless, some of the most abundant particle types are dominated either by organic/carbonaceous components (e.g., soot, secondary organic aerosol particles) or by inorganic components (e.g., sea salt, mineral dust). Traditionally the total carbon (TC) content of air particulate matter is defined as the sum of all carbon contained in the particles, except in the form of inorganic carbonates. TC is usually determined by thermo-chemical oxidation and evolved gas analysis $\left(\mathrm{CO}_{2}\right.$ detection), and divided into an organic carbon (OC) fraction and a black carbon (BC) or elemental carbon (EC) fraction, respectively. Measurements of $\mathrm{BC}$ and $\mathrm{EC}$ are generally based on optical or thermo-chemical techniques, respectively, and $\mathrm{OC}$ is operationally defined as the difference between $\mathrm{TC}$ and $\mathrm{BC}$ or $\mathrm{EC}$, respectively $(\mathrm{TC}=\mathrm{BC}+\mathrm{OC}$ or $\mathrm{TC}=\mathrm{EC}+\mathrm{OC}$ ). However, there is no real sharp cut but a continuous decrease of thermo-chemical refractiveness and specific optical absorption going from graphite-like structures to non-refractive and colourless organic compounds, respectively. Both BC and EC may be thought of as the carbon content of the graphite-like material usually contained in soot (technically defined as the black product of incomplete combustion or pyrolysis of carbonaceous materials) and other combustion aerosol particles, which can be pictured as more or less disordered stacks of graphene layers. Depending on the applied optical or thermo-chemical methods (absorption wavelength, temperature gradient, etc.), however, $\mathrm{BC}$ and $\mathrm{EC}$ measurements also respond to variable amount of coloured and refractory organic compounds ("brown carbon"), which can lead to substantially different results between methods. This strongly limits the comparability and suitability of BC, $\mathrm{EC}$, and OC data for the determination of mass balances and physicochemical properties of air particulate matter (MayolBracero et al., 2002; Bond et al., 2004; Bond and Bergstrom, 2006; Pöschl, 2005). The term "brown carbon" refers to the carbon content of light-absorbing organic aerosol components (mostly of high molecular mass and resembling humic or fulvic acids) with a steep increase of absorption toward ultraviolet and short visible wavelengths (Kirchstetter et al., 2004; Hoffer et al., 2005; Andreae and Gelencsér, 2006).

At first sight, some of the above distinctions may appear trivial. A clear, precise, and universally applicable distinction between the listed terms is, however, indispensable for efficient investigation and consistent description of atmospheric aerosol sources, interactions, and effects as detailed below. The references given above and throughout the rest of this manuscript are meant to support the statements made here, but they do not provide a comprehensive overview of the large and rapidly growing body of scientific literature on organic aerosols, which would go beyond the scope of this article.

\section{Sources of organic aerosols}

Source strengths, transformations, and removal rates of OA must be represented with reasonable accuracy in order to constrain the abundance of this aerosol. In addition, properties such as water uptake characteristics, optical properties, and ability to serve as cloud or ice nuclei must be known in order to understand the behaviour of this aerosol in the atmosphere, as well as its climatic and health impacts. This section will discuss how source-centred approaches can be improved to constrain OA regional and global burdens and atmospherically relevant properties.

OA has been classified in two ways: by sources (e.g., anthropogenic vs. biogenic) and by properties (e.g., black carbon vs. organic carbon; hydrophobic vs. hydrophilic, etc.). It remains to be established to what degree there is a one-to-one pairing between these categories. Here we suggest a preliminary source classification (Table 1), within which aerosol properties can be determined. We recommend use of this set of source designations to facilitate integration and comparison of disparate OA measurements across the globe. In some cases there is consensus within the OA community as to these source class definitions. However, further discussion is needed in defining the others, as discussed below.

Bottom-up estimates of organic aerosol sources will always be uncertain. It is therefore necessary to use atmospheric measurements, which represent the real state of the atmosphere, to constrain estimates of source strength. Several general classes of measurements can assist in this regard. We recommend an effort by the urban air-quality community, 
Table 1. Suggested classification of organic aerosols by source type. Italics indicate distinguishing features that can uniquely identify a source.

\begin{tabular}{|c|c|c|c|}
\hline Class & Designation & Sample components & Distinguishing characteristics \\
\hline 1.1 & Biogenic POA & $\begin{array}{l}\text { Organic particles \& compounds of biological } \\
\text { origin, including whole organisms (e.g., bacte- } \\
\text { ria), reproductive material (e.g., pollen, spores), } \\
\text { fragments (e.g., plant waxes), and decaying } \\
\text { biomass }\end{array}$ & $\begin{array}{l}\text { Morphology; molecular, elemental } \\
(\mathrm{K}, \mathrm{P}) \text { \& isotopic markers }\left({ }^{14} \mathrm{C}\right) ; \\
\text { EC/OC ratio; seasonality }\end{array}$ \\
\hline 1.2 & Biogenic SOA & $\begin{array}{l}\text { Organic particles \& compounds originating } \\
\text { from the atmospheric transformation of chemi- } \\
\text { cal species of biological origin }\end{array}$ & $\begin{array}{l}\text { Molecular \& isotopic markers } \\
\left({ }^{14} \mathrm{C}\right) ; \mathrm{EC} / \mathrm{OC} \text { ratio; seasonality }\end{array}$ \\
\hline 2.1 & Fossil Fuel Combustion POA & $\begin{array}{l}\text { Organic particles \& compounds originating } \\
\text { from fossil fuel combustion (condensable at } \\
\text { ambient temperature) }\end{array}$ & $\begin{array}{l}\text { Molecular, elemental \& isotopic } \\
\text { markers }\left({ }^{14} \mathrm{C}\right) \text {; seasonality }\end{array}$ \\
\hline 2.2 & Fossil Fuel Combustion SOA & $\begin{array}{l}\text { Organic particles \& compounds originating } \\
\text { from the atmospheric transformation of chemi- } \\
\text { cal species emitted from fossil fuel combustion }\end{array}$ & $\begin{array}{l}\text { Molecular \& isotopic markers } \\
\left({ }^{14} \mathrm{C}\right) \text {; seasonality }\end{array}$ \\
\hline 3.1 & Bio-Fuel Combustion POA & $\begin{array}{l}\text { Organic particles \& compounds originating } \\
\text { from bio-fuel combustion (condensable at am- } \\
\text { bient temperature) }\end{array}$ & $\begin{array}{l}\text { Morphology; molecular \& elemen- } \\
\text { tal markers }(\mathrm{K}, \mathrm{P}) \text {; seasonality }\end{array}$ \\
\hline 3.2 & Bio-Fuel Combustion SOA & $\begin{array}{l}\text { Organic particles \& compounds originating } \\
\text { from the atmospheric transformation of chemi- } \\
\text { cal species emitted from bio-fuel combustion }\end{array}$ & $\begin{array}{l}\text { Molecular \& isotopic }\left({ }^{14} \mathrm{C}\right) \text { mark- } \\
\text { ers; seasonality }\end{array}$ \\
\hline 4.1 & $\begin{array}{l}\text { Anthropogenic Non-Combustion } \\
\text { POA }\end{array}$ & $\begin{array}{l}\text { Organic particles \& compounds originating } \\
\text { from anthropogenic processes other than fuel } \\
\text { combustion and biomass burning (condensable } \\
\text { at ambient temperature) }\end{array}$ & $\begin{array}{l}\text { Molecular \& elemental markers } \\
\text { (trace metals, minerals); seasonality }\end{array}$ \\
\hline 4.2 & $\begin{array}{l}\text { Anthropogenic Non-Combustion } \\
\text { SOA }\end{array}$ & $\begin{array}{l}\text { Organic particles \& compounds originating } \\
\text { from the atmospheric transformation of chem- } \\
\text { ical species emitted from anthropogenic pro- } \\
\text { cesses other than fuel combustion and biomass } \\
\text { burning }\end{array}$ & $\begin{array}{l}\text { Molecular \& isotopic markers } \\
\left({ }^{14} \mathrm{C}\right) \text {; seasonality }\end{array}$ \\
\hline 5.1 & Open biomass burning POA & $\begin{array}{l}\text { Organic particles \& compounds originating } \\
\text { from open biomass burning (natural fires and } \\
\text { land-use practices) }\end{array}$ & $\begin{array}{l}\text { Morphology; molecular \& elemen- } \\
\text { tal markers }(\mathrm{K}, \mathrm{P}) \text {; seasonality }\end{array}$ \\
\hline 5.2 & Open biomass burning SOA & $\begin{array}{l}\text { Organic particles \& compounds originating } \\
\text { from the atmospheric transformation of chemi- } \\
\text { cal species emitted from open biomass burning }\end{array}$ & $\begin{array}{l}\text { Molecular \& isotopic markers } \\
\left({ }^{14} \mathrm{C}\right) \text {; seasonality }\end{array}$ \\
\hline 6.1 & Sea-spray POA & $\begin{array}{l}\text { Organic particles \& compounds dispersed in } \\
\text { sea spray }\end{array}$ & $\begin{array}{l}\text { Molecular and elemental markers; } \\
\text { size-segregated composition; sur- } \\
\text { face tension }\end{array}$ \\
\hline
\end{tabular}

which has done much work on constraining sources, to compile a review of the literature available on the issue. Several intensive field studies have been conducted for this purpose.

While we have recommended the use of source (rather than property) classification, we believe that classification by source, shown in Table 1, and classifications by climaterelevant properties should begin to converge. It is essential to better represent the climate-relevant properties of OA, in addition to simply its mass loading because these properties will allow for source attribution through "fingerprinting" (i.e., via the "Distinguishing characteristics" in Table 1) and also for determining the climatic impact of OA, such as through their light-absorbing properties and activation properties as cloud condensation or ice nuclei. Thus, the sourceoriented classifications discussed here need to be linked with the physical and chemical properties discussed in the following paragraphs.

\subsection{Outstanding issues for future research}

Above we have argued that organic aerosol measurements be classified by source, and have suggested a classification scheme (Table 1). Nonetheless, it remains an open question as to what source-related definitions of OA are the clearest 
and most useful. It may be that the categories given in Table 1 will need to change as more is learned about atmospheric OA, but in order to reduce uncertainties in organic aerosol source strengths and properties it will be critical that a consistent classification scheme and a uniform set of definitions are used by the OA research community. Keeping this in mind, the first steps at reducing these uncertainties will need to address the following key questions:

1. What are the uncertainties in "bottom-up" estimates, so that research efforts can be focused on the most important uncertainties?

2. What is the best suite of analytical methods to attribute measured OA to particular sources or processes?

3. How closely can near-source measurements constrain emission rates and climate-relevant properties of $\mathrm{OA}$ ?

4. How can field measurements (intensive campaigns and continuous monitoring) best be used to assess model inputs and processes?

\subsubsection{Definitions}

Two of the classes suggested in Table 1 (primary biogenic and ocean-generated $\mathrm{OA}$ ) have received little attention, but preliminary evidence suggests that they could be important for atmospheric processes (Andreae and Crutzen, 1997; Monn, 2001; O'Dowd et al., 2004; Randles et al., 2004; Leck and Bigg, 2005). We recommend that literature reviews be prepared on these topics to assess what is known about their magnitude and potential importance.

Some of the classes listed in Table 1 require further community discussion to achieve consensus, with specific attention to the distinction between primary and secondary aerosol components (see Sect. 2.4) and to the classification of bio-fuel emissions. In fact, bio-fuel has historically (e.g., IPCC) been lumped with open biomass burning (i.e., Class 5 in Table 1) as a source. However, estimating bio-fuel emissions is similar to estimating fossil-fuel emissions because the two are burned for similar purposes. We recommend that bio-fuel emissions be considered together with emissions from closed combustion (i.e., Classes 3 and 4 in Table 1), while acknowledging that this classification does not allow a clear separation between the anthropogenic and open biomass categories that are based on isotopic measurements.

\section{Uncertainties in "bottom-up" estimates}

A range of challenges are involved in "bottom-up" emission estimates for each of the OA classes listed in Table 1. However, the modelling framework for each class is similar: some factor representing source quantities (e.g., leaf area index for some biogenic emissions and fuel use for primary anthropogenic emissions) is multiplied by an emission factor (e.g., moles per $\mathrm{m}^{2}$ leaf area per hour for some biogenic emissions). Each pathway has similar types of uncertainties, such as fuel quantity used or the question of the representativeness of any measured emission or yield factor.

Understanding the sources of variation in both proxies and emission factors is important in two critical endeavours: i) understanding whether emission characteristics measured in one region are transferable to another region; and ii) understanding how emissions will change under different climatic regimes. The "bottom-up" framework will allow to address these questions, and the community needs to pursue this representation, although not exclusively.

The need to address the changing emissions and characteristics makes it clear that dynamic models, rather than static inventories, must become state-of-the-art. For example, in a dynamic model simulation of the global biogenic secondary organic aerosol (Class 1.2) emissions respond to temperature as shown in Fig. 3 for isoprene. Similarly, pyrogenic emissions from closed combustion (Classes 2.1 through 3.2) will grow as fuel consumption increases, and change as different fuels are selected. Such interactions will be particularly important for investigating the net response of the earth system to global change. These models will require a judicious balance between representations of the important physical mechanisms, while at the same time excluding unnecessary complexity such as tertiary processes that cannot be confirmed empirically. Synergistic use of such dynamic models, together with the traditional flux measurements and the satellite observations of proxy compounds, the latter being a technique that is presently emerging, is expected to provide a step forward in reducing the OA sources uncertainties. Similarly to biogenic secondary organic aerosol (SOA) precursor emissions, the uncertainty in the emissions of primary organic aerosol (POA) from sea-spray can be reduced by targeted studies that combine tracer measurements in the sea surface and in the marine boundary layer with air-sea exchanges models and satellite observations.

At present, only some of the source classes shown in Table 1 have at least some existing modelling framework, and there are large uncertainties associated with each of them. In contrast, other source classes require preliminary investigations before model estimates can be generated. While a final prioritization of research efforts to reduce these uncertainties should be based on model sensitivity studies, Table 2 provides a preliminary list of recommended strategies to pursue the largest uncertainties (from a bottom-up viewpoint) in each of the four classes for which a modelling framework is currently available.

\section{Attribution}

The ability to physically and/or chemically distinguish different fractions of $\mathrm{OA}$ is critical to constraining source estimates. Presently, poor comparisons between predictions and measurements of OA cannot be attributed to errors or 
Table 2. Priorities for uncertainty reduction.

\begin{tabular}{|c|c|c|}
\hline Classes & Designation & Next Steps \\
\hline $2.1,3.1$ & Fuel Combustion POA & $\begin{array}{l}\text { Representative emission factors and climate-relevant properties for major sources; fuel- } \\
\text { use assessments for bio-fuels }\end{array}$ \\
\hline $5.1,5.2$ & Open biomass burning POA \& SOA & Large-scale parameterizations, including relationships with fire conditions \\
\hline 6.1 & Sea-spray POA & $\begin{array}{l}\text { Quantify representative emission rates and determine if this is a significant contributor } \\
\text { to global atmospheric OA. }\end{array}$ \\
\hline
\end{tabular}

uncertainties in any single source class, limiting the ability to confirm emission estimates in each class. Development and widespread application of techniques to apportion OA among the different classes (i.e., source "fingerprinting") should be given a high priority. A starting point for this activity are the "Distinguishing Characteristics" shown in Table 1. Emphasis should be on quantitative attribution to confirm emission predictions and on identifying source classes that need further study. Examples include, but are not limited to:

1. isotopic composition $\left({ }^{14} \mathrm{C}\right)$ for differentiating between modern and fossil carbon. (If sources do not include bio-fuel, this method can distinguish anthropogenic from biogenic carbon);

2. further development of unique source and process markers;

3. application of source-apportionment techniques, including factor analysis;

4. exploration of techniques such as Aerosol Mass Spectrometry (AMS), including soft-ionization, that provide size-resolved composition information.

Finally, these techniques should be used to constrain not only mass loading/concentration predictions but also the properties of OA and OA components.

\section{Near-source measurements}

Field campaigns near specific source types and under the simplest possible situations (i.e., minimizing other sources, transport and conversion time, removal, etc.) will have the greatest utility for testing the bottom-up approach to quantifying source emissions. Such measurements should be conducted in places where the source term is much larger than the loss and transformation terms, such as regions dominated by a single source (e.g., biogenic emissions or biomass burning) or in plumes. Global models may be used to identify such regions, and regional models could test the detailed assumptions regarding the impacts of sources on concentrations at the measurement location. Careful integration of several measurement approaches will be needed to provide the combination of spatial detail and time-resolution necessary to constrain the most important aerosol properties and distributions, including vertical profiles. For example, one might make fast airborne in-situ measurements of proxies with instruments like the Aerodyne AMS. Lidar measurements could then be used to scale those in-situ measurements over cross-plume sections. Slower, more specific measurements from the surface, tethered balloons, or towers would also be needed to relate the proxy measurement to the actual species of interest. This could be done using detailed measurements such as scanning electron microscopy, molecular markers, functional group analyses, and other approaches. Flux measurements of biogenic emissions provide another example of integrating approaches: micrometeorological, mass balance, and tracer ratio methods can be conducted on a variety of platforms including handheld, tower, blimp, and aircraft. We recommend that specific observational strategies aimed at source-model testing be incorporated into the mega-city experiments that various programs are planning, such as IGAC's Mega-cities Task, the Monsoon Asia Integrated Regional Study, and the MIRAGE Mexico City campaign.

In addition to constraining source mass emissions, measurements near sources can assist in the task of determining the climate-relevant properties of OA. Some properties are largely determined at or near the source, such as the abundance of light-absorbing soot particles. Other properties, such as particle hygroscopicity, are influenced by atmospheric history and processing. For example, pyrogenic aerosols can become larger, more hygroscopic and more soluble as they age (Rissler et al., 2006). The properties 
that can be constrained with near-source measurements should be identified, and field measurements should be designed to determine the relevance of near-source measurements to properties of OA throughout the atmosphere. If transformations of these properties occur rapidly, then the near-source properties need not be represented in models, and representative properties would need to be obtained by another method. Aircraft studies of plume aging processes (tracking an air parcel as it travels downwind of a source) are needed to quantify these transformations and characterize their time scales. This is true regardless of whether the plume is from a fire, a power plant stack or an isolated forest.

\section{Integrated measurements on a variety of scales}

It is frequently useful to characterize concentration fields on several different spatial and time scales to gain a complete understanding of the processes controlling emissions from a particular source. Measurements on a range of spatial scales (from $<1 \mathrm{~km}^{2}$ to the entire earth system) and time scales (from seconds to years) are desirable. Integrated measurement-modelling approaches, including inverse modelling and assimilation of satellite data, will also suggest areas in which source characterization can be improved.

Ultimately, we have to demonstrate that models integrating sources, transformation processes, transport, and removal are consistent with atmospheric measurements. Because meteorology has a large impact on atmospheric concentrations, a statistically significant number of samples are needed for a large range of emission and meteorological pairings. Thus time-series measurements combined with modelling studies lasting several years are needed to confirm their consistency. These time-series should include markers and properties that can be related to specific source types. Associated measurements may include a combination of in-situ and remote sensing data.

Source strengths are one set of the many model inputs that can be varied to make models and observations agree, so specific attention should be paid to designing some of the models and time-series observations to isolate the impact of source changes from that of changes in atmospheric processing, transport, etc. Examples might be seasonal changes in building heating or field burning, which could be detected in aerosol time-series observations and attributed to specific source changes. The design of the time-series studies should also include explicit identification and testing of other atmospheric processes.

\section{Formation and transformation of organic aerosols}

In addition to constraining source strengths and aerosol properties at the source, it is critical that we understand how OA and their precursors are transformed in the atmosphere and the dependence of the transformation on the chemical and thermodynamic conditions of the ambient environment. This is needed for two main reasons: i) to accurately forecast how changing emissions will impact atmospheric organic aerosol concentrations and properties on the regional to global scale, and ii) to connect atmospheric measurements with sources. As noted above, a large (but as yet un-quantified) fraction of organic aerosol is formed in the atmosphere by precursor gases. While the basic mechanisms for aerosol formation are identified, the details of these processes are not. In addition, both primary and secondary OA interact with other gas and aerosol species in the atmosphere so that their properties (i.e., size, hygroscopicity, light absorption and scattering efficiency) can change significantly with time and distance from their source.

Gaseous organic components can be transformed into aerosol and incorporated into existing particles by several pathways:

1. partitioning of semi-volatile organic compounds (SVOC) from the gas phase into/onto pre-existing particles. Note that SVOC can be formed by atmospheric oxidation of VOC or directly emitted into the atmosphere from biogenic or anthropogenic sources, such as vegetation and combustion emissions (e.g., aldehydes like nonanal, and polycyclic aromatic hydrocarbons like pyrene);

2. participation of SVOC and NVOC (low- or non-volatile organic compounds) in the formation of new particles (nucleation);

3. formation of NVOC by heterogeneous or multiphase reactions of VOC or SVOC on the surface or in the bulk of aerosol and cloud particles.

Until recently, most studies of SOA formation had focused on the formation of SVOC by gas phase oxidation of biogenic and anthropogenic VOC (e.g., monoterpenes and benzene derivatives) and on their gas-to-particle conversion via pathways a) or b). Several recent studies, however, indicate that pathway c) may also play an important role in SOA formation in the atmosphere. In addition, VOC which had previously been assumed not to contribute to organic aerosol formation have been positively identified as SOA precursors (e.g., isoprene and benzene) (Claeys et al., 2004; Gao et al., 2004; Kalberer et al., 2004; Tolocka et al., 2004; Martian-Reviejo and Wirtz, 2005). These studies have shown that organic compounds with high molecular masses (oligomers/polymers, humiclike substances (HULIS), mostly < $500 \mathrm{Da}$ ) can be formed from VOC or SVOC by acid-catalysed or radical oligo- or polymerisation reactions involving photo-oxidants and sulphuric acid, dilute aqueous solutions, or freshly formed OA particles.

The formation of new aerosol particles from gas phase molecules generally proceeds via the nucleation of 


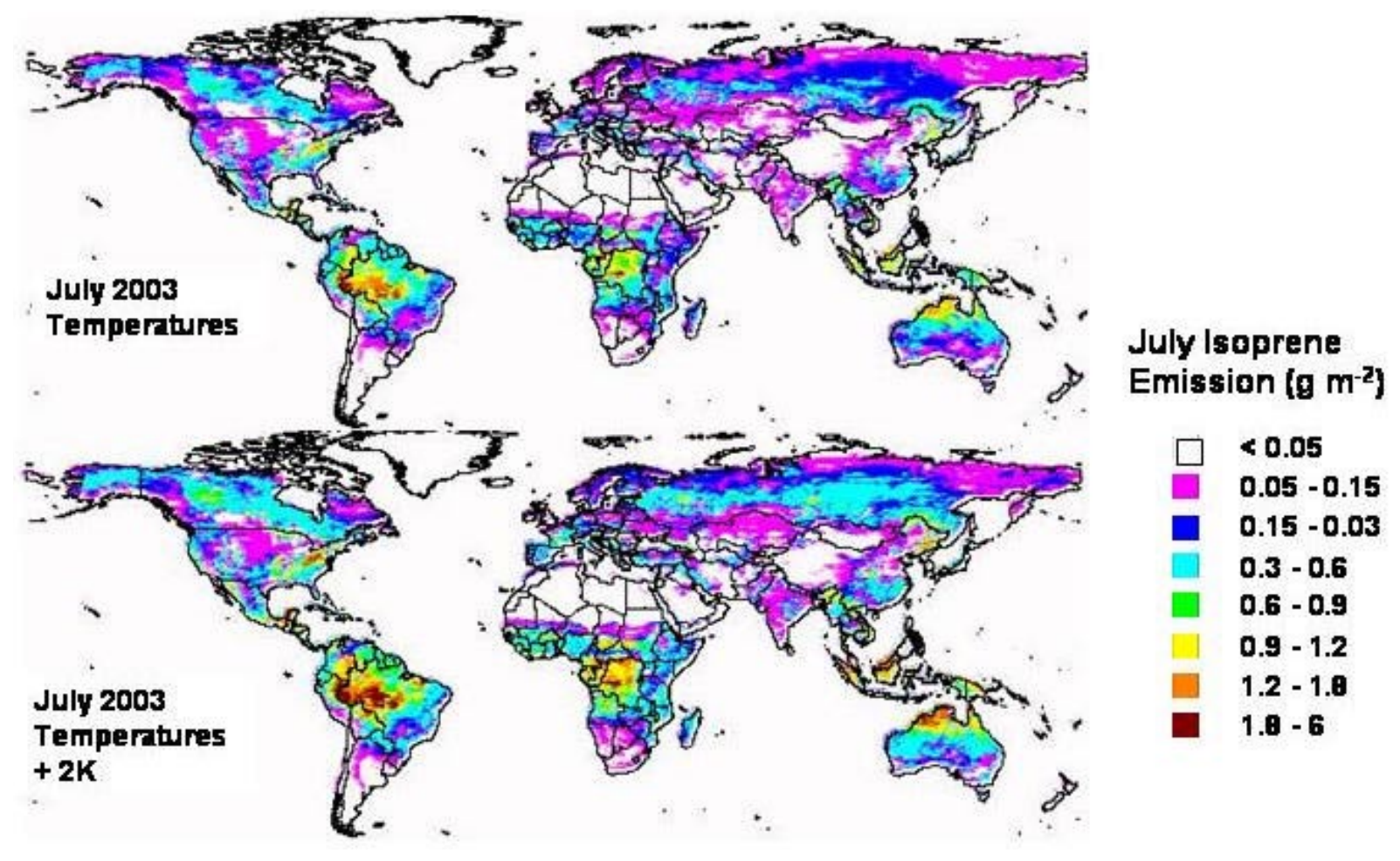

Fig. 3. Response of global isoprene emission rate distributions to a $2 \mathrm{~K}$ increase in temperature. Emissions estimated by the MEGAN emission model (http://bai.acd.ucar.edu/MEGAN) for July 2003 (top) are compared with estimates where temperatures have been increased by $2 \mathrm{~K}$ (bottom).

nanometre-sized molecular clusters and subsequent growth by condensation (Kulmala, 2003). Experimental evidence from field measurements and model calculations suggests that the formation of new organic particles in the atmosphere may be dominated by ternary nucleation of $\mathrm{H}_{2} \mathrm{SO}_{4}$ $\mathrm{H}_{2} \mathrm{O}-\mathrm{NH}_{3}$ and subsequent condensation of organic vapours (SVOC) (Kulmala et al., 2004, 2005). Laboratory experiments, on the other hand, indicate that SVOC may also play a role in the nucleation process if the concentrations of condensable vapours are high enough.

Physical and chemical aging processes can efficiently change the properties and environmental effects of aerosols. Under atmospheric conditions, OA particle components (POA as well as SOA) can undergo a wide range of chemical reactions (oxidation, nitration, hydrolysis, photolysis, polymerisation, etc.), and the interaction of OA components with inorganic ions/electric charge, water vapour and clouds can influence the physical structure of aerosol particles (envelope shape and porosity, phase separation and transition, etc. (Mikhailov et al., 2004).

The chemical aging of OA components essentially follows the generic reaction pathways outlined in Fig. 4, and it tends to increase the oxidation state and water solubility of OC. In analogy to atmospheric gas phase photochemistry of VOC, oxidation, nitration, hydrolysis, and photolysis transform hy- drocarbons and derivatives with one or few functional groups into multifunctional hydrocarbon derivatives. The cleavage of organic molecules and release of SVOC, VOC, $\mathrm{CO}$ or $\mathrm{CO}_{2}$ can also lead to a volatilization of organic particulate matter (OPM). On the other hand, oxidative modification and degradation of biopolymers may convert these into HULIS (analogous to the formation of humic substances in soil, surface water, and groundwater processes). Moreover, condensation reactions and radical-initiated oligo- or polymerization can decrease the volatility of OA components and promote the formation of SOA particulate matter (SOA oligomers or HULIS, respectively). Oxidation and nitration reactions can also influence the toxicity and allergenicity of air particulate matter (Pöschl, 2002; Bernstein et al., 2004; Schauer et al., 2004; Franze et al., 2005).

The actual reaction mechanisms and kinetics, however, have been elucidated and fully characterized only for a small number of model reaction systems and components. So far, most progress has been made in the investigation and modelling of chemical reactions in cloud droplets. For the reasons outlined above, very few reliable and widely applicable kinetic parameters are available for organic reactions at the surface and in the bulk of liquid and solid aerosol particles.

The formation and transformation of atmospheric aerosol particles and components generally proceeds via multiple 


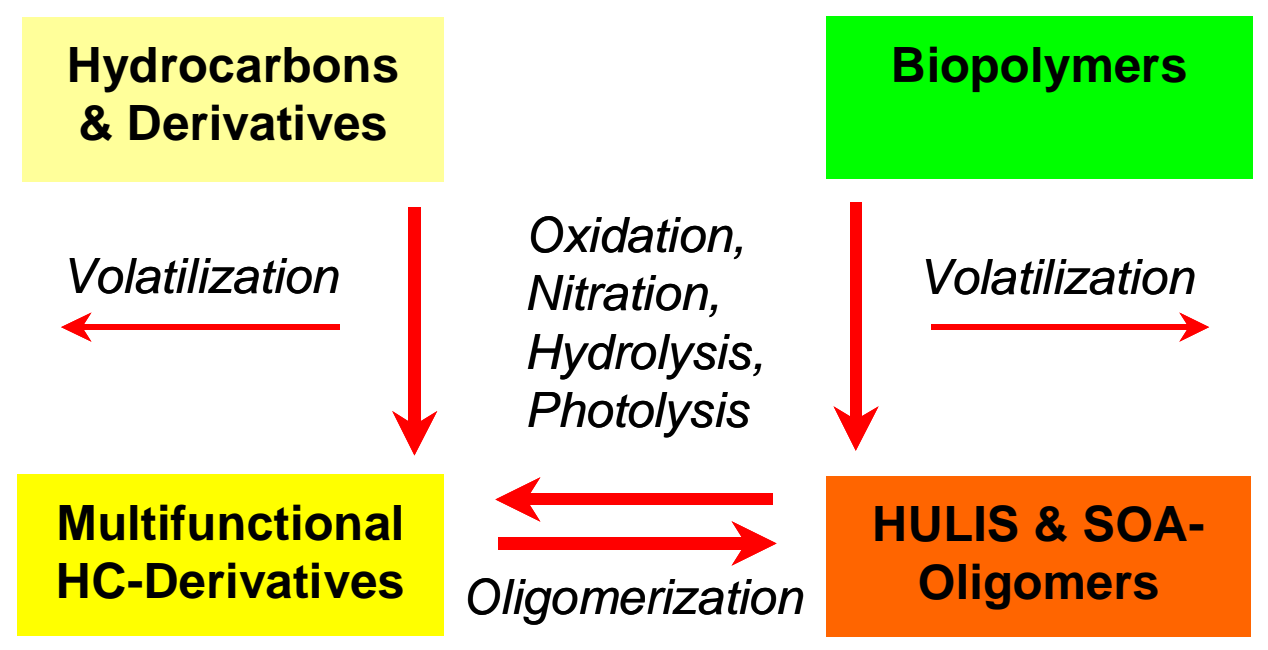

Fig. 4. Generic reaction pathways for the atmospheric transformation (chemical aging) of organic aerosol components (left side: low molecular mass; right side: high molecular mass; Pöschl, 2005).

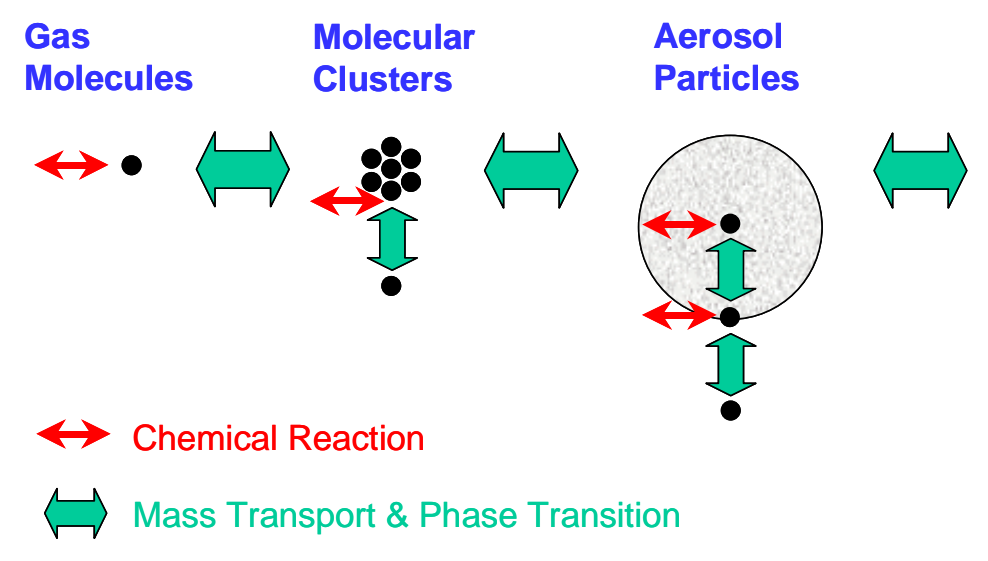

\section{Cloud \& Precipitation Particles}

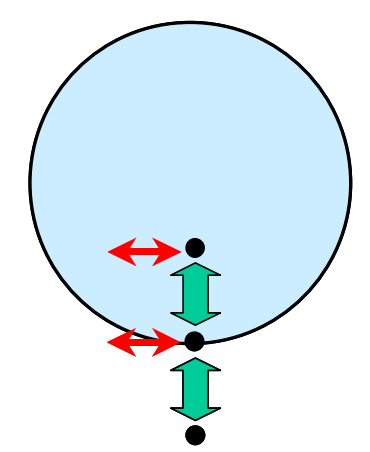

Fig. 5. Schematic illustration of the formation and transformation of atmospheric aerosol particles and components: mass transport and phase transitions in and between gas phase, clusters, aerosol, cloud and precipitation particles; chemical reactions in the gas phase, at the interface, and in the particle bulk (Pöschl, 2005; Pöschl et al., 2005).

steps of mass transport and chemical reaction in and between the gas phase, molecular clusters, aerosol, cloud, and precipitation particles (multiphase processes and heterogeneous reactions; Fig. 5). The combination of gas and liquid diffusion, reversible and competitive adsorption, and surface and bulk reactions usually leads to non-linear concentration and time dependencies and limits the applicability of linear extrapolations and steady-state assumptions. For a reliable mechanistic understanding and quantitative description of OA formation and transformation, the involved physico-chemical processes have to be deconvoluted and characterised by universally applicable formalisms and rate coefficients. A kinetic model framework for consistent and efficient description of aerosol and cloud surface chemistry and gas-particle inter- actions has recently been proposed by Pöschl et al. (2005). It builds on a simple double layer surface model and enables formal separation and, depending on the required level of detail and available information, flexible separation or convolution of elementary molecular processes in the gas phase, at the gas-particle interface, and in the particle bulk (Fig. 6).

\subsection{Outstanding issues for future research}

For each of the above transformation pathways (SOA formation, new particle formation, and organic aerosol ageing) a specific set of open questions and research priorities emerges. In some cases there is overlap, such as the need for more laboratory studies under atmospherically relevant conditions. The complexity of these processes and our current 


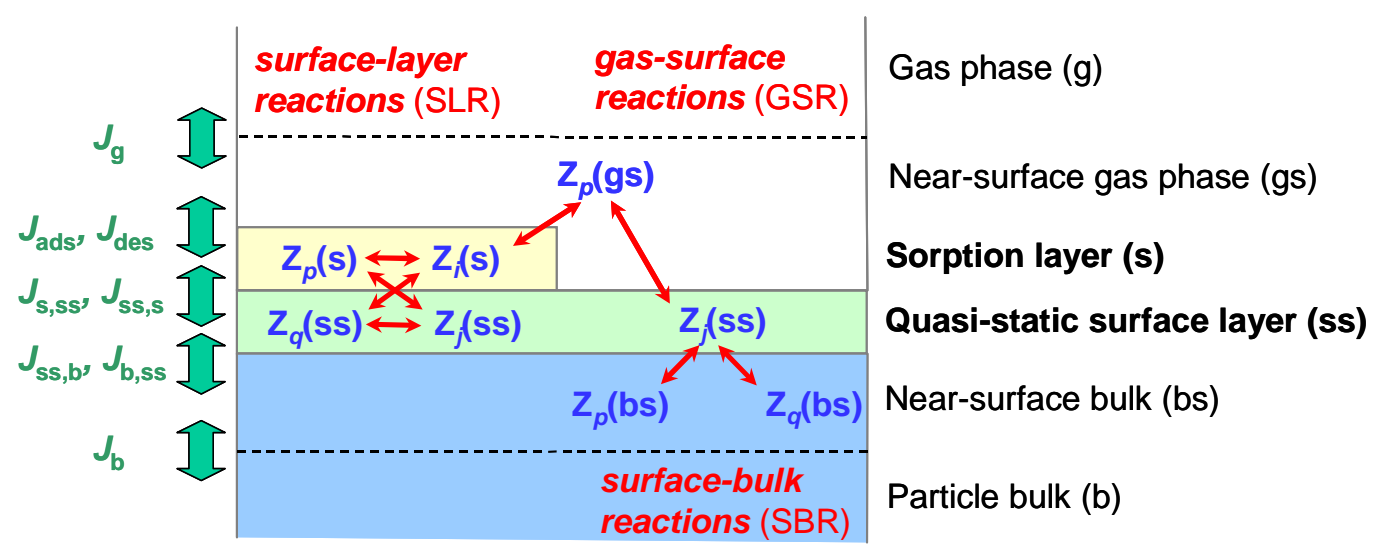

Fig. 6. Double-layer surface model, transport fluxes (bold green arrows), and chemical reactions (slim red arrows) of semi-volatile aerosol components $(Z x)$ at a gas-particle interface (Pöschl et al., 2005).

lack of understanding of them means that detailed studies in both laboratory and field environments are needed. At the same time, because there is a need to represent these processes in models there is an emphasis on identifying the most important processes. In addition, it is critical that we identify areas where simplification is possible, such as through parameterizations or the grouping of similar species/processes.

4.1.1 Open questions on secondary organic aerosol (SOA) formation

1. How important is SOA formation in the atmosphere (OA vs. inorganics; SOA vs. POA), and how does it influence the properties and environmental effects of atmospheric aerosols?

2. How important are the different SOA formation pathways relative to each other; in particular, how important are heterogeneous reactions on aerosols and multiphase reactions in clouds relative to each other and relative to gas phase oxidation followed by gas-to-particle conversion?

3. What are the molecular mechanisms and kinetics of the chemical and physical processes involved?

4. What are the most important precursors of SOA formation (VOC, SVOC; biogenic/natural vs. anthropogenic)?

5. What are the most important products of SOA formation (organic acids, oligomers/polymers, HULIS, etc.) and what are their physico-chemical properties (functional groups, molecular mass, stability, volatility, solubility, hygroscopicity, optical absorption, etc.)?

6. How can SOA components be experimentally identified and quantified (discrimination from POA and black/elemental carbon (BC/EC), positive and negative sampling and measurement artefacts)?

7. What is the relative contribution of SOA components to organic OC and particulate organic matter (POM, the total mass of organic matter including elements besides carbon)? What is the range of values of the POM/OC conversion factor for the various types of SOA?

8. What are suitable SOA marker/tracer/model compounds and how can the countless individual SOA components be classified and lumped for efficient description of SOA formation and properties in atmospheric models?

9. Are SOA formation rates, temperature, $\mathrm{CO}_{2}$ concentration, photosynthesis, biogenic VOC emission, and aerosol concentration coupled in an efficient climate feedback mechanism?

\subsubsection{Open questions on new particle formation}

1. Do organics participate in nucleation? If yes, how and to which extent?

2. Does the mechanism of new particle formation and the influence of organics depend on location, season, altitude, etc.? If yes, how and to which extent?

3. What is the effect of ions/electric charge on nucleation, growth and the influence of organics?

4. Which organics are most important for the growth of new particles by condensation, and which (if any) are important for nucleation?

5. Are the organic compounds involved in new particle formation different than the bulk of SOA components (i.e., those that either remain in the gas phase or that condense directly onto existing particles)? 
6. How can the organics involved in new particle formation be determined in laboratory experiments and field measurements?

\subsubsection{Open questions on organic aerosol aging}

1. How do aging processes influence the physico-chemical properties of OA components, in particular their volatility, solubility, hygroscopicity, and optical absorption (e.g., formation of light-absorbing and hygroscopic species)?

2. How does the chemical transformation of OA by atmospheric photo-oxidants (air pollutants) influence aerosol health effects (e.g., the enhancement of mutagenicity and allergenicity by nitration of polycyclic aromatic hydrocarbons in soot and proteins in bioparticles, respectively)?

3. How do OA components and their aging influence the kinetics of aerosol particle interactions with reactive trace gases, water vapour and clouds (e.g., kinetic limitations to mass transport and phase transitions like particle deliquescence and efflorescence, evaporation and adsorption/absorption of semi-volatile organics and inorganics, etc.)?

4. What are the mechanisms and kinetics of OA aging processes (heterogeneous and multiphase chemical reactions; mass transport and phase transitions; surface and bulk effects), and how can they be efficiently described in atmospheric models?

5. How do transformations upon sampling, storage, and measurement influence the chemical and physical analysis of OA (e.g., filter reactions, gas-particle partitioning, shape transformation, etc.)?

6. Can aging of OA by heterogeneous reactions followed by evaporation of smaller molecular weight products (Molina et al., 2004) be an important sink for OA and for atmospheric oxidants?

\section{Physical and chemical state of organic aerosols}

The diverse chemical and physical properties of aerosol particles that contain organic compounds control the role they play in the atmosphere, affecting i) their gas-particle partitioning, ii) their water uptake in sub-saturated conditions, iii) their water uptake in supersaturated conditions, iv) their nucleation of ice, and v) their light scattering and absorption.

The measurement of OA composition has involved a multifaceted approach, drawing on a number of complementary instruments. The instruments that exist today vary in the type of method used, ranging from approaches that quantify individual molecular species to ones that characterize only partial molecular fragments or bonds. Examples of speciated approaches include liquid or gas chromatography coupled with mass spectrometry (LC-MS), whereas aerosol ablation and ionization can be used with mass spectrometry to characterize fragments, and infrared (IR) spectroscopy measures absorption by bonds. Some of the techniques that have been applied to characterizing organic aerosol are listed in Table 3.

Since information on the complete molecular composition of organic particles is impossible to obtain with existing techniques and is unlikely to be realized in the foreseeable future, current strategies need to include both improvements to existing instrumentation and a method for characterizing OA using techniques that do not rely on full chemical speciation. Simultaneously, existing measurement techniques should be exploited to characterize organic composition with propertybased approaches. To this end, the use of model compounds which can simulate the chemical and physical properties of OA has been proposed (Fuzzi et al., 2001, 2002; Decesari et al., 2006) and should further be exploited.

A further issue is that organic aerosol measurements are often seriously affected by positive and negative artefacts during sampling, also limiting the accuracy to which we can fully characterise and understand OA composition. For instance, transformation processes of the organic component of aerosols occur not only in the atmosphere but also during aerosol sampling and measurement, frequently leading to substantial analytical artefacts (in some cases up to $100 \%$ of measurement values; Schauer et al., 2003). Various techniques have been developed to overcome this problem but the issue of artefact aerosol organic carbon is far from being solved.

In addition, Evolved Gas Analysis (EGA, the basic type of analysis to separate EC and OC in atmospheric aerosol) suffers from many shortcomings and uncertainties still remain unacceptably large for OA characterisation and the distinction of the organic and "elemental" fractions (see e.g. review by Novakov et al., 2005).

In addition to the issues with measurement techniques, there are also complicating factors as to how to interpret the results of these measurements and use them to make generalized statements about OA properties.

Water uptake in sub-saturated conditions is typically described as "hygroscopic growth" characterized by a diameter-based ratio of the change in particle size, where growth is either monotonic (simple exponential) or deliquescent (exponential, but with a very rapid increase in size around a given relative humidity, $R H$ ). Evidence exists suggesting that particle-phase organic compounds enhance water uptake by atmospheric particles in some cases and inhibit or retard water uptake in other cases (Saxena and Hildemann, 1996), in particular affecting water uptake at low $R H$. For example, Marcolli et al. (2004) have noted that mixtures of organics can retain water and remain in the liquid phase even at very low $R H$. On the other hand, the presence of organics (particularly more soluble organics) can also lower the $R H$ at which deliquescence of the aerosol occurs (Kanakidou et 
Table 3. Measurement techniques for organic aerosols.

\begin{tabular}{|c|c|c|}
\hline Level of Speciation & Technique & Related Works ${ }^{1}$ \\
\hline \multirow[t]{3}{*}{ Molecules } & Gas Chromatography-Mass Spectrometry (GC-MS) & Hildemann et al., 1991 \\
\hline & Liquid Chromatography-Mass Spectrometry (LC-MS) & Odum et al., 1996 \\
\hline & Ion Chromatography (IC) & Mochida et al., 2003 \\
\hline \multirow[t]{5}{*}{ Molecular Fragments } & Aerosol Time-of-Flight Mass Spectrometry (ATOMS) & Guazzotti et al., 2003 \\
\hline & 2-Step Laser Desorption/Ionisation Mass Spectrometry & Morrical et al., 1998 \\
\hline & Time-of-Flight $2^{\circ}$ Ion Mass Spectrometry & Tervahattu et al., 2002 \\
\hline & Electron Impact (EI) Time-of-Flight Mass Spectrometry & Bahreini et al., 2003 \\
\hline & Electrospray Mass Spectrometry & Kalberer et al., 2004 \\
\hline \multirow[t]{3}{*}{ Molecular Bonds } & Proton Nuclear Magnetic Resonance (HNMR) & Decesari et al., 2000 \\
\hline & Infrared Spectroscopy (IR) & Maria et al., 2003 \\
\hline & $\begin{array}{l}\text { Near-Edge X-Ray Absorption Fine Structure Spectroscopy and } \\
\text { Scanning Transmission X-Ray Microscopy (NEXAFS/STX) }\end{array}$ & Russell et al., 2002 \\
\hline \multirow[t]{2}{*}{ Elemental Composition } & Evolved Gas Analysis (EGA) & Turpin et al., 2000 \\
\hline & Scanning and Transmission Electron Microscopy (SEM/TEM) & Husar and Shu, 1975 \\
\hline Isotopic Composition & $\begin{array}{l}\text { Gas Chromatography/Online Combustion/Isotope Ratios Mass } \\
\text { Spectrometry (GC/irMS) } \\
\text { Accelerator Mass Spectrometry (AMS) }\end{array}$ & Szidat et al., 2004 \\
\hline
\end{tabular}
${ }^{1}$ These references are reported as examples of the use of the listed techniques and are by no means exhaustive of the many papers, which
have reported on organic aerosol analysis by these and other techniques.

al., 2005). While the ability of dissolved inorganic ions in aerosol particles to take up water is well understood, theoretically and experimentally, little information exists about the hygroscopic behaviour of particles containing organic compounds. The mechanism of water uptake by particles that contain organic species has been studied recently in several laboratory experiments, but most of these results describe the behaviour of pure organic compounds in water or of mixtures of organic compounds with an inorganic salt, whereas real atmospheric aerosol, particularly in polluted regions, is almost always a complex mixture of organic and inorganic aerosols, the latter of which may include soot and/or dust, as well as chemically active gas species. Complex mixtures of organic compounds have been characterized by semi-empirical thermodynamic models of properties, but these model results need to be validated (Marcolli et al., 2005; Topping et al., 2005; Mircea et al., 2005).

The phase of components in particles plays a key role in determining how particles take up water. Compounds that are mixed in dry conditions will tend to stay mixed as they take up water. Compounds that are not mixed in dry solid or liquid particles will tend to take up water in separate stages, as required by the Gibbs Phase Rule. The behaviour of well-mixed liquids differs considerably from water uptake by components that are not mutually soluble in dry conditions.

Another important aspect of the behaviour of OA in the atmosphere is their ability to serve as condensation nuclei for cloud droplets in supersaturated conditions. Laboratory studies on hygroscopic growth of different polar organic compounds have demonstrated that water-soluble organics in the atmospheric aerosol could act as important cloud condensa- tion nuclei (CCN) or ice nuclei (IN) (Marcolli et al., 2004; Hartz et al., 2005; Svenningsson et al., 2006). This role is also important in determining the microphysical properties of clouds as well as the deposition of particles in lungs. Classical theory for ideal solutions of dissociated inorganic ions shows that the Raoult effect competes with the Kelvin effect in the water uptake process (Köhler, 1936). The result is heterogeneous nucleation of droplets with sufficient energy from dissolution of ions to overcome the barrier created by the formation of an expanded air-water interface. This picture of cloud condensation nuclei depends nearly exclusively on the solubility and surface tension of organic compounds in particles (Nenes et al., 2002). Recent work suggests that surface wettability may also play a role in describing the non-ideal solution properties associated with the complex mixtures present in organic particles in the atmosphere (Raymond and Pandis, 2002). In addition, the presence of trace amount of inorganic salts can also significantly alter the ability of organic aerosols to form cloud droplets (Bilde and Svenningsson, 2004; Broekhuizen et al, 2004).

The influence of OA particles in changing the properties of ice-forming nuclei in mixed-phase clouds is poorly understood, as is also their role in ice crystal formation within cirrus clouds. In one study it was noted that ice cloud particles preferentially contained sulphate (versus organic) aerosol, indicating that the organics were not as efficient as ice nuclei (Cziczo et al., 2004). Another study concluded that the presence of organics will not have a significant impact on cirrus formation unless they comprise a very high fraction of the ambient aerosol (Kärcher and Koop, 2004). 
Organic aerosols also contribute to the optical properties of atmospheric particles (i.e., their light scattering efficiency and absorption efficiency) which are governed by hygroscopicity, absorption, phase and mixing, and other properties. Hygroscopic growth plays an important role in the direct radiative effect of aerosol by enhancing light scattering, resulting in reductions in visibility and incoming solar radiation. Organic particles will both absorb and scatter radiation. It is known that absorption by black carbon has an important effect on the atmospheric radiative balance, but the relative and absolute roles of back carbon and light-absorbing organic aerosol ("brown carbon") in absorbing radiation is not well constrained (Andreae and Gelencser, 2006). Quantifying light-absorbing carbon, and the associated organic carbon that is typically mixed with soot-like emissions, requires careful measurements and multiple techniques. The few measurements of absorption by typical atmospheric organic compounds show very small absorption, but both particle phase and its associated shape have important impacts on the calculated scattering and absorption of light in the atmosphere and individual organic components exhibit a wide range of scattering and absorption indices (Fig. 7). External and internal mixing of components may change the calculated optical effects significantly (Jacobson, 2001; Myhre and Nielsen, 2004).

\subsection{Outstanding issues for future research}

For the last decade, studies of molecular compositions of OA have been conducted extensively using GC/MS, LC/MS, IC, etc. Previous molecular approaches demonstrated that organic aerosols are composed of complex mixture of different organic species from less-polar organics (n-alkanes, polycyclic aromatic hydrocarbons, fatty alcohols, fatty acids, etc.) to highly polar organics such as dicarboxylic acids and multi-functional organic acids. Studies employing FTIR spectroscopy and NEXAFS have demonstrated the presence of different functional groups such as ketonic and carboxylic groups in aerosol particles. Humic-like substances (HULIS) have been identified in aerosols, although their contribution to organic carbon is not clear. Field observation and laboratory smog chamber studies demonstrated that oxidative reactions of biogenic and anthropogenic OA precursors in the gas phase produce low molecular weight organic acids such as oxalic and other dicarboxylic acids, dicarbonyls and multifunctional organics. Oxidation reactions in the particle phase may also produce oxygenated species, including aldehydes, organic acids, and large molecules such as HULIS. Despite this research progress, a significant fraction of atmospheric OA still remains poorly characterized.

Future analytical research should expand our knowledge of OA to provide i) direct relationships to primary and secondary sources of particulate organics, ii) properties of the mixtures present in organic particles, and iii) chemical reactivity of components in particle mixtures. One path to provid- ing these three types of information is quantitative, molecular speciation of every compound present in aerosol particles, followed by development of a detailed model linking this molecular composition to the source origins, physical, and chemical of the resulting mixtures. The second path uses property-driven lumping to estimate mixture behaviour in the absence of complete speciation. We believe that both paths should continue to yield fruitful insights on organic aerosol, and that their parallel implementation will significantly advance our understanding in the next decade. The relationship between sources and their organic emissions provides a critical link to understanding how organic particles form. Characterizing organic emissions from individual sources is a formidable challenge, because of the cost of measuring the diverse and dispersed types of activities that produce organics. Currently most countries lack specific regulations on organic emissions. Before we can effectively identify sources of global organic emissions we will need to effect changes in policy.

The mixture properties of the OA determine their impact on the atmosphere. One example of physical properties for organic particles that remains an outstanding research issue is the optical properties of OA. Characterizing the absorption of sunlight in the atmosphere by particles requires paying careful attention to absorbing organic compounds in particles and the wavelength dependence of their absorption. Measuring optical properties in mixtures of micron-sized particles provides an outstanding technical challenge that merits future instrument development. Solubility, hygroscopicity, and wettability also represent important properties of aerosol behaviour in the atmosphere that are not yet well characterized or understood.

The third type of properties needed are the chemical reactivities, describing the reactions of components that lead to changes in OA composition. Chemical evolution of OA in the atmosphere modifies distributions of functional groups, thus altering the mixture properties (e.g. hygroscopicity, solubility, wettability, ice nucleation capability, optical characteristics). One example is that small dicarboxylic acids can act as agents to dissolve clay and carbonate minerals (dusts) and accelerate the release of metals into the liquid phase of aerosols and may thereby be linked to biogeochemical cycles of micronutrients in the remote atmosphere and ocean. Future studies will need to characterize these potential changes in composition during atmospheric transport.

\section{Atmospheric modelling of organic aerosols}

Using models, we can integrate knowledge on sources of organic species, their transport, formation, transformation, and properties (chemical, physical and optical) with the thermodynamics and meteorology of the ambient atmosphere in order to determine the effects of $\mathrm{OA}$ on the biosphere and human health, their radiative impacts, effects on the 

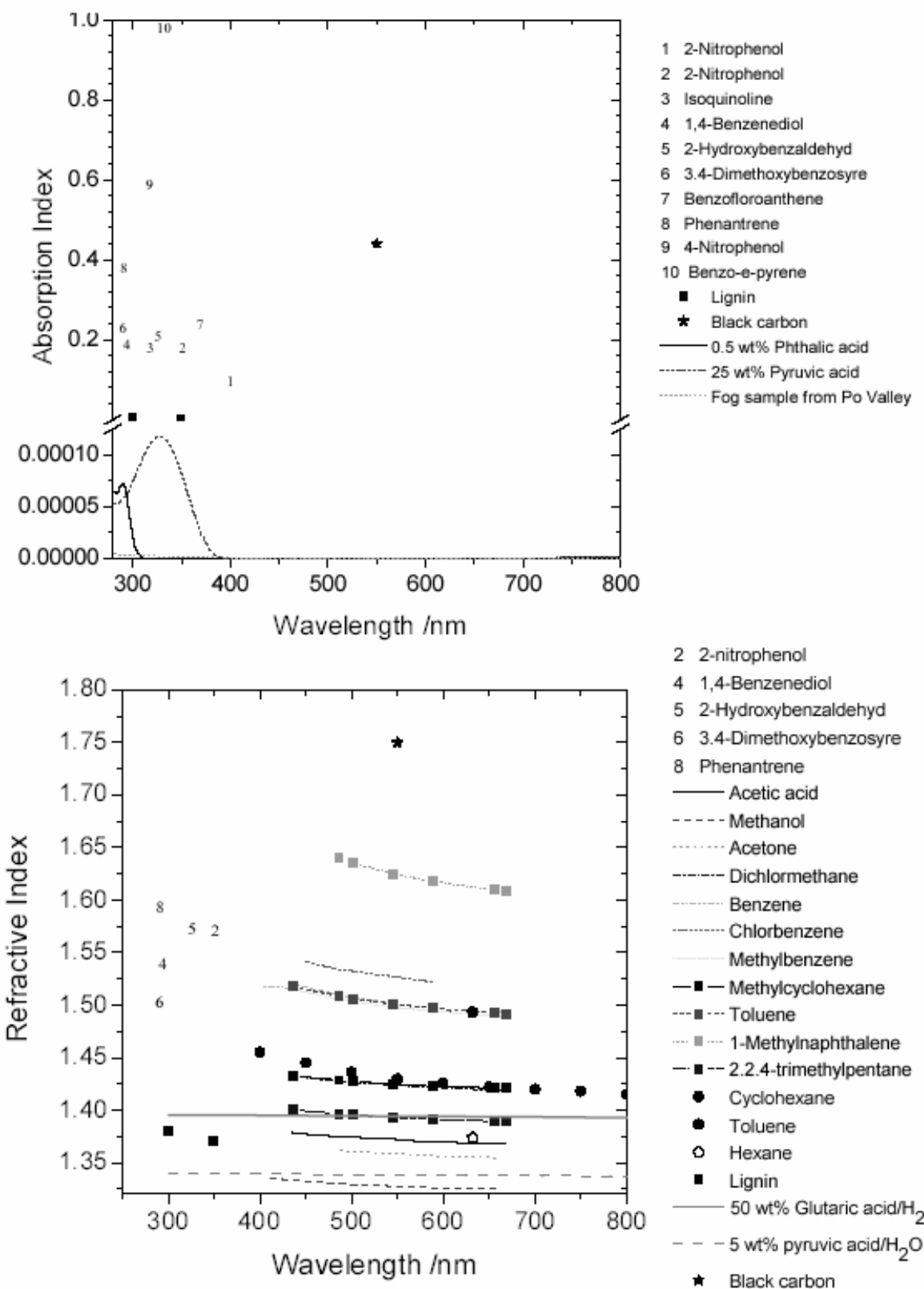

2 2-nitrophenol

4 1,4-Benzenediol

5 2-Hydroxybenzaldehyd

6 3.4-Dimethoxybenzosyre

8 Phenantrene

Acetic acid

- - - - Methanol

....... Acetone

------ Dichlormethane

-....... Benzene

-..--..- Chlorbenzene

Methylbenzene

-m-Methylcyclohexane

--- -- Toluene

.... 1-... - Methylnaphthalene

-.--2.2.4-trimethylpentane

- Cyclohexane

- Toluene

- Hexane

- Lignin

-50 wt \% Glutaric acid/ $/ \mathrm{H}_{2} \mathrm{O}$

--5 wt $\%$ pyruvic acid $/ \mathrm{H}_{2} \mathrm{O}$

- Black carbon

Fig. 7. Shown is the absorption index (top) and the real refractive index (bottom) of several organics and forms of black carbon, for wavelengths between about $\sim 250-800 \mathrm{~nm}$. The compounds shown present some overlap (i.e. common compounds studied) but are not all the same (Kanakidou et al., 2005).

hydrological cycle and, from that, their climate impacts. As has been discussed above, field measurements have revealed a very large number of organic species in the atmosphere in both the gas and particulate phases. The behaviour of these species depends on their mass fractions relative to one another and to inorganic species (such as $\mathrm{SO}_{2}, \mathrm{NO}_{\mathrm{x}}, \mathrm{O}_{3}$, nitrate, sulphate, and black carbon) as well as on temperature and humidity, all of which will likely evolve with time and climatic conditions. The complexity of the processes controlling atmospheric aerosols can only be captured using small-scale, high resolution models which are capable of simulating physical and chemical processes in great detail. These models can yield insight into how perturbations in atmospheric composition and climate might affect organic aerosol formation rates and properties (i.e., sensitivity studies) and the concomitant impacts on aerosol distribution as well as, for example, cloud droplet formation and wet and dry deposition of these aerosols. However this level of chemical and microphysical detail cannot be extended to the global scale due to computational limitations, so radiative and climate impacts 

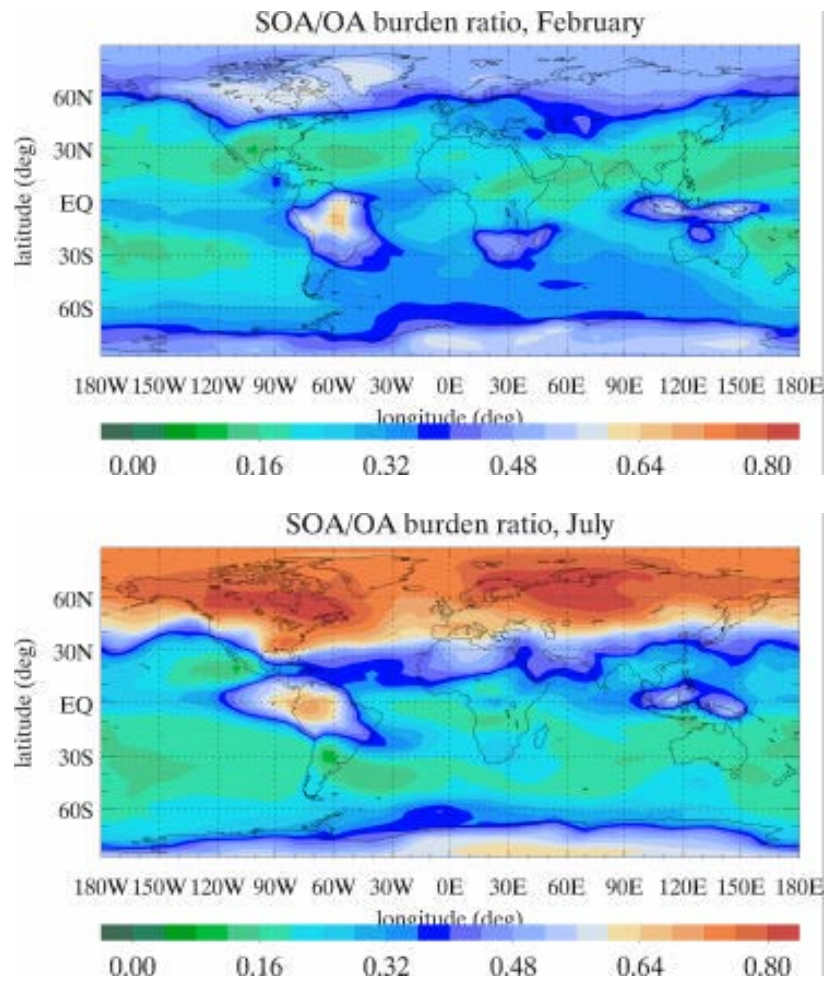

Fig. 8. The ratio of secondary to total organic aerosol at the surface (top) and the vertical profile of SOA/OA for the month of July (bottom; Kanakidou et al., 2005; Tsigaridis et al., 2005).

must be determined using a hierarchy of models from process models over regional models to global scale (Johnson et al., 2006a, b).

Information and improvements are needed in order to reduce uncertainties in Chemical Transport Model (CTM) and Global Climate Model (GCM) representations of OA. Currently, there is about a factor-of-three uncertainty in the direct plus indirect top-of the-atmosphere radiative effect of OA (IPCC, 2001), so these uncertainties are large. A significant part of this stems from a lack of understanding of SOA formation rates and their controlling factors, though source strengths (for both OA and precursor gases), transformation and removal processes, the aerosol optical properties, and organics' effects on cloud formation and lifetime also remain highly uncertain. Depending on the aerosol sources, transport processes, and atmospheric conditions, the composition of OA can be dominated either by POA or by SOA. For example, recent studies have shown a high abundance of POA in tropical air masses that are influenced by strong biomass burning (Artaxo et al., 2002; Formenti et al., 2003; Kirchstetter et al., 2003; Decesari et al., 2006). On the other hand, in extra-tropical air masses, influenced by anthropogenic or biogenic emissions of precursor VOC and characterized by high photochemical activity, most of the aerosol is produced in the atmosphere from gaseous precursors (cf. Kanakidou et al., 2005 and Fig. 8).
In addition to basic knowledge about OA, there is a need to improve the representation of the physical and chemical characterization of OA component in models. Effort needs to focus on modelling (i) the size resolved multi-component aerosol, allowing consideration of internally mixed aerosol; (ii) the formation of SOA, including mechanisms other than gas-to-particle partitioning; and (iii) the impact of organics on aerosol optics, on water associated with the aerosol, on cloud formation, growth and properties (Kanakidou et al., 2005).

\subsection{Outstanding issues for future research}

To consider organic aerosols in CTMs and GCMs we need to identify which are the critical parameters for controlling OA formation and fate under both pristine and polluted conditions and to identify suitable parameterisations of processes too complex to be included in full detail. This requires improvement of our understanding of the physical and chemical behaviour of OA such that we can simplify the system without missing critical information on the complex organic/inorganic mixtures of the different aerosol types (marine, urban, rural, etc).

To properly include OA properties in models, we need to have better knowledge in the following critical areas:

1. The total three-dimensional mass and size distribution and temporal variability of $\mathrm{OA}$ in the atmosphere. This depends on sufficiently constrained knowledge of emissions, physical and chemical transformation processes, and removal rates from the atmosphere via dry deposition and precipitation. In particular, the simulation of the formation and occurrence of SOA in the troposphere requires the development of "clever" lumping methods, using a small number of species that represent the necessary properties for modelling and which are suitable for present-day and pre-industrial conditions.

2. The optical properties of OA (absorption/scattering) and information on solubility, hygroscopicity and the ability of $\mathrm{OA}$ to activate as cloud condensation nuclei $(C C N)$ and ice nuclei (IN). These properties need to be defined/parameterized at the particle level involving mixtures of numerous organic components. We also need to know and simulate the state of mixing of organics with the other aerosol constituents in the atmosphere and understand how their mixing state impacts their physical, optical and hygroscopic properties.

In Table 4 we summarize the specific information needed at the very small scale and that are needed at the scale represented in CTMs and GCMs, and we suggest that the need to link the two scales may be met by the use of functional grouping of organic species. Information about molecular functional groups might offer a means for deducing the minimum number of surrogate compounds for OA in models. 
Table 4. Information needed for atmospheric modelling of organic aerosols.

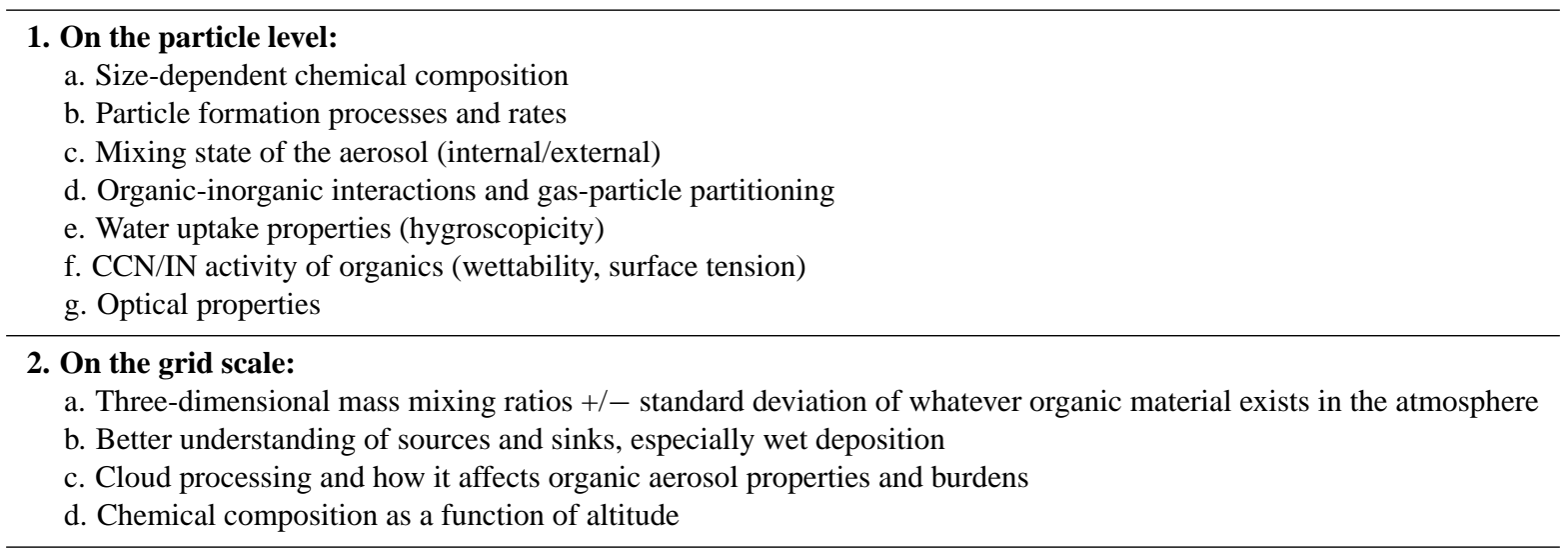

An issue with some of the properties listed in Table 4 is that measurements will not necessarily yield information in the form needed by modellers. For example, models typically calculate aerosol optical properties by taking a mass mixing ratio, distributing it over a lognormal size distribution, calculating a mass-weighted index of refraction (real and imaginary), and then use Mie theory to calculate the aerosol scattering and absorption properties. While mass mixing ratio and size distributions are routinely measured in the field, index of refraction is not. Instead, mass scattering and absorption efficiencies and the single scattering albedo (ratio of scattering to scattering-plus-absorption) are measured. Also, accurate determination of index of refraction relies on full chemical characterization, which because of the high chemical complexity of real atmospheric OA is not generally accomplished. Thus the measured optical properties are useful for validation, but not for model input. Similarly, particle formation rates and processes cannot be measured directly but must be inferred from measurements at various points downwind of sources (i.e., Lagrangian type experiments).

In addition to the improvements to model inputs, the model representations of certain processes need to be improved. Formation of OA from gas species within the atmosphere deserves special attention, both because of the difficultly of representing this process in models and because of what the models can teach us. For example, SOA is formed in the whole tropospheric column and not only close to the surface. Model calculations have shown that only about half of it is formed in the lowest $6 \mathrm{~km}$ in the troposphere, and the percentage contribution of the secondary fraction to the total OA mass increases with height (Kanakidou et al., 2005). The sensitivity of OA chemical formation to various parameters has been studied by comparing different transport/chemistry models for the same case study and in comparing different cases with the same CTM (Pun et al., 2003; Tsigaridis and Kanakidou, 2003). These results point out the impor- tance of the "lumping" of groups of chemical constituents in model representations. The major factor of uncertainty seems to be the temperature dependence of the partitioning of constituents between gas and particulate phases. Recent experimental studies of oligomer formation of OA (Kalberer et al., 2004; Tolocka et al., 2004; Gao et al., 2004) suggest a new approach of SOA modelling that involves multiphase and aerosol chemistry (Kanakidou et al., 2005 and references therein). The uncertainty in the emissions of the VOC that lead to SOA formation is propagated to the SOA formation, but not linearly since oxidant levels are also affected by VOC emissions.

Improvement is also needed in how models treat OA hygroscopicity. Currently, most models assume that OA is initially hydrophobic, then use a fixed e-folding time to transform them to a uniform level of hygroscopicity. This is critical for three reasons: i) aerosol optical depth (i.e., the OA direct radiative impact) is highly dependent on the aerosol hygroscopicity in high humidity regions - such as the boundary layer where OA are most likely to reside; ii) the water uptake properties of the aerosol will strongly affect its ability to act as CCN (i.e., the OA indirect effect); and iii) the removal, and thus atmospheric burden, of OA will be impacted by how easily OA are incorporated into clouds. The simplified parameterisation of the conversion of OA from hydrophobic to hydrophilic that is currently being used in models needs to be replaced by a more physically and chemically based parameterisations. In addition, improvement of cloud and precipitation parameterizations (stratiform and convective) in GCMs must be a major point of action (Lohmann and Feichter, 2005).

Models will ultimately be improved through close collaborations between modellers and those conducting laboratory and field measurements and by investigating OA in the context of the full earth system. In turn, the measurement community can optimize the utility of their measurements using model results. 


\section{Recommended research directions}

Because of the OA particularly complex chemical composition and of the degree to which OA can be altered chemically and physically in the atmosphere it is unlikely that we will ever be able to fully represent the state of all organic species throughout their lifetime in the atmosphere. Progress on resolving the many open questions delineated above requires a research approach, where: i) the most critical questions are identified and addressed first; ii) uniform terminology (Sect. 2) is used by the whole research community; iii) simplifications, such as functional grouping, are applied wherever possible and with consistency; iv) laboratory, field measurement and modelling research is well-coordinated. Based on the previous discussions, we propose the following set of research objectives for future research:

\section{R1: Improvements to measurement techniques}

1. Development and application of powerful and efficient analytical techniques for the identification and quantification of SOA components in laboratory experiments and field measurements. (e.g., online and single particle aerosol mass spectrometry, optical spectroscopy, chromatography, isotope analysis).

2. Development and optimisation of physical and chemical measurement techniques for nanometre-sized particles, clusters, and ions (ion spectrometer, single particle MS).

3. Further improvement of artefact-free aerosol sampling for organic compounds and standardize the BC/OC separation procedure through EGA.

4. Understanding of organic compositions at the functional group or structural level is still an important subject of OA study in terms of bulk-, size-segregated and individual aerosol particles. Developments of new methods and technologies are needed to better describe the chemical composition of OA.

5. Spatial distributions of functional groups within an individual particle further need to be studied, because such chemical states determine the physical properties of aerosols.

\section{R2: Laboratory and environmental chamber experiments}

1. More laboratory and environmental chamber experiments under atmospherically relevant conditions are needed to elucidate:

i) SOA formation pathways, in particular heterogeneous and multiphase reaction pathways;

ii) organic aerosol aging processes.

2. The mechanism and kinetics of the involved physical and chemical processes need to be understood. These studies should be combined with chemical modelling studies at different scales.

3. Laboratory studies to elucidate the mechanisms and kinetics of nucleation and growth of new particles and to gather thermodynamic data of SOA components as a function of temperature and composition (surface tensions, densities, vapour pressures, activities).

4. Laboratory studies under controlled conditions, investigating the role of organic aerosols as ice nuclei in conditions characteristic of the upper troposphere.

5. Laboratory studies on the heterogeneous reactions that result in small and highly oxygenated species as well as large polymers (HULIS), with various organic precursors of biogenic and anthropogenic origin.

6. Laboratory studies of aerosol water uptake (i.e. hygroscopicity and activation) for OA and OA mixed with inorganic species and soot.

\section{R3: Field measurements}

1. Field measurements on new particle formation, with comprehensive physical and chemical analysis of particles, clusters, and ions, and with detailed meteorological data.

2. Tests and validation of laboratory, chamber and model results by combining a Lagrangian observational approach with air parcel and process models (see, for example, Lohmann and Leck, 2005).

3. Lagrangian or pseudo-Lagrangian studies to study how the properties of aerosol aerosols/components evolve from emission at the source to locations downwind, both before and after cloud-processing.

4. Integrated regional studies in regions shown to have high sensitivity in climate models.

5. Field measurements studying the role of OA in the nucleation processes (e.g., ice crystal formation) in clouds in the upper troposphere.

6. Field measurements of small and highly oxygenated species as well as large polymers (HULIS), with various organic precursors of biogenic and anthropogenic origin. These results should be synthesised with what is learned from laboratory studies (i.e. R2 d) above), with the goal of understanding (and, ideally, being able to parameterize) the heterogeneous reactions involved in the OA formation.

7. Investigation on the degree to which source categories (i.e. Table 1) are correlated with aerosol properties (i.e. "Defining characteristics" in Table 1). This will allow 
studies that use(d) source classification to be synthesized with those that have used classification by aerosol properties.

8. Coordinated measurements of aerosol water uptake (i.e. hygroscopicity and activation) and chemical composition for a range of real atmospheric aerosol.

9. Involvement of modellers in the planning for and interpretation of data from field experiments.

\section{R4: Model evaluation and development}

1. Model evaluation:

i) use of regional models to evaluate the representativeness of observational sites;

ii) extension of these results to the GCM scale;

iii) use of regional models to infer subgrid-scale information needed on GCM scale.

2. Use of in-situ data (especially vertical/high altitude information), surface observations and remote sensing for model evaluation.

3. Improved collaborations between climate modellers and the air quality and health communities. Use the wealth of data from air quality monitoring to improve models.

4. Derivation of simplified parameterisations (lumping of species and processes) for atmospheric CTMs (regional and global).

5. Development of detailed process models and master mechanisms describing:

i) mass transport

ii) chemical reactions of organic and inorganic compounds in aerosols and clouds

iii) organic trace gas and aerosol chemistry (VOC, SVOC, NVOC)

iv) new particle formation, including nucleation, growth, aerosol dynamics, sulphur and organic chemistry as well as the role of ions/electric charge.

The use of consistent and universally applicable formalisms and terminology is particularly important in this context.

\section{R5: Application of models}

1. Sensitivity studies of new particle formation and organic aerosol aging, using detailed process models and simplified atmospheric models.

2. Modelling studies that include comprehensive and coupled dynamics, vegetation, cloud microphysics and chemistry to understand and describe aerosol-cloud interactions.
3. Perturbation studies, looking at the dynamical, physical and chemical state of clouds.

4. Involve modellers in field experiments for:

i) the planning and interpretation of field measurements;

ii) use of climate models to define sensitive regions for integrated regional studies;

iii) use of chemical forecasting in the realization of the field experiments.

\section{Conclusions}

OA are clearly a significant fraction of atmospheric particulate matter, which has a large impact on aerosol physical and chemical properties. Unfortunately, OA chemical complexity and the technical limitations of present analytical tools have frustrated attempts to characterize OA. As a result, OA impact cannot presently be described adequately in chemical transport and climate models. The research agenda outlined in this paper aims at assisting in prioritizing research in this critical area of the geosciences. A set of self-consistent terms for describing OA, has also been suggested and is expected to enhance clarity in discussing within the scientific community of atmospheric and climate research OA sources, properties, interactions, and effects.

Acknowledgements. This paper results from a workshop convened by the three atmosphere-related projects of the International Geosphere Biosphere Programme (IGBP): IGAC (International Global Atmospheric Chemistry Project), iLEAPS (Integrated Land Ecosystem Atmosphere Process Study) and SOLAS (Surface Ocean-Lower Atmosphere Study), with the specific goal of discussing and prioritizing issues related to organic aerosol and their effects on atmospheric processes and climate, providing a basis for future collaborative activities at the international level. The authors want to thank all of the workshop participants for their contribution. The excellent organisation of the workshop which was held at the Hyytiälä (Finland) field station on 10-12 May, 2004 was provided by the University of Helsinki which hosted the workshop and supported the local expenses of the participants. Tanja Suni of the iLEAPS Project Office competently handled the whole organisation. Travel funding was provided by the Seattle IGAC Project Office, the Bologna IGAC Project Office through the European Network of Excellence ACCENT, and the International SOLAS Project Office through SCOR. The comments and suggestions of three anonymous reviewers greatly helped in improving the final manuscript. M. Kanakidou acknowledges the EU project PHOENICS for support.

Edited by: S. Martin 


\section{References}

Andreae, M. O. and Crutzen, P. J.: Atmospheric aerosols: Biogeochemical sources and role in atmospheric chemistry, Science, 276, 1052-1056, 1997.

Andreae, M. O. and Gelencsér, A.: Black carbon or brown carbon? The nature of light-absorbing carbonaceous aerosols, Atmos. Chem. Phys. Discuss., 6, 3419-3463, 2006.

Artaxo, P., Martins, J. V., Yamasoe, M. A., Procópio, A. S., Pauliquevis, T. M., Andreae, M. O., Guyon, P., Gatti, L. V., and Leal, A. M. C.: Physical and chemical properties of aerosols in the wet and dry season in Rondonia, Amazonia, J. Geophys. Res., 107, 8081, doi:10.1029/2001JD000666, 2002.

Bahreini, R., Jimenez, J. L., Wang, J., Flagan, R. C., Seinfeld, J. H., Jayne, J. T., and Worsnop, D. R.: Aircraft-based aerosol size and composition measurements during ACE-Asia using an Aerodyne aerosol mass spectrometer, J. Geophys. Res., 108, 8645, doi:10.1029/2002JD003226, 2003.

Bernstein, J. A., Alexis, N., Barnes, C., Bernstein, I. L., Nel, A., Peden, D., Diaz-Sanchez, D., Tarlo, S. M., and Williams, P. B.: Health effects of air pollution, J. Allergy Clin. Immunol., 114, 1116-1123, 2004.

Bilde, M. and Svenningsson, B.: CCN activation of slightly soluble organics: importance of state of mixing and particle humidity history, Tellus, 56B, 128-134, 2004.

Bond, T. C., Streets, D. G., Yarber, K. F., Nelson, S. M., Woo, J. H., and Klimont, Z.: A technology-based global inventory of black and organic carbon emissions from combustion, J. Geophys. Res., 109, 14 203, doi:10.1029/2003JD003697, 2004.

Bond, T. C. and Bergstrom, R. W.: Light absorption by carbonaceous particles: An investigative review, Aerosol Sci. Technol., 40, 1-41, 2006.

Broekhuizen, K., Kumar, P. P., and Abbatt, J. P. D.: Partially soluble organics as cloud condensation nuclei: Role of trace soluble and surface active species, Geophys. Res. Lett., 31, L01107, doi: 10.1029/2003GL018203, 2004.

Claeys, M., Wang, W., Ion A. C., Kourtchev I., Gelencser, A., and Maenhaut, W.: Formation of secondary organic aerosols from isoprene and its gas-phase oxidation products through reaction with hydrogen peroxide, Atmos. Environ., 28, 4093-4098, 2004.

Cziczo, D. J., DeMott, P. J., Brooks, S. D., Prenni, A. J., Thomson, D. S., Baumgardner, D., Wilson, J. C., Kreidenweis, S. M., and Murphy D. M.: Observations of organic species and atmospheric ice formation, Geophys. Res. Lett., 31, L12116, doi:10.1029/2004GL019822, 2004.

Decesari, S., Facchini, M. C., Fuzzi, S., and Tagliavini, E.: Characterization of water-soluble organic compounds in atmospheric aerosol: A new approach, J. Geophys. Res., 105, 1481-1489, 2000.

Decesari, S., Fuzzi, S., Facchini, M. C., Mircea, M., Emblico, L., Cavalli, F., Maenhaut, W., Chi, X., Schkolnik, G., Falkovich, A., Rudich, Y., Claeys, M., Pashynska, V., Vas, G., Kourtchev, I., Vermeylen, R., Hoffer, A., Andreae, M. O., Tagliavini, E., Moretti, F., and Artaxo, P.: Characterization of the organic composition of aerosols from Rondônia, Brazil, during the LBASMOCC 2002 experiment and its representation through model compounds, Atmos. Chem. Phys., 6, 375-402, 2006.

Formenti, P., Elbert, W., Maenhaut, W., Haywood, J., Osborne, S., and Andreae, M. O.: Inorganic and carbonaceous aerosols during the Southern African Regional Science Initiative (SAFARI
2000) experiment: Chemical characteristics, physical properties, and emission data for smoke from African biomass burning, J. Geophys. Res., 108, 8488, doi:10.1029/2002JD002408, 2003.

Franze, T., Weller, M. G., Niessner, R., and Pöschl, U.: Protein nitration by polluted air, Environ. Sci. Technol., 39, 1673-1678, 2005

Fuzzi, S., Decesari, S., Facchini, M. C., Matta, E., Mircea, M., and Tagliavini, E.: A simplified model of the water soluble organic component of atmospheric aerosols, Geophys. Res. Lett., 28, 4079-4082, 2001.

Fuzzi, S., Facchini, M. C., Decesari, S., Matta, E., and Mircea, M.: Soluble organic compounds in fog and cloud droplets: what have we learned over the past few years?, Atmos. Res., 64, 89-98, 2002.

Gao, S., Ng, N. L., Keywood, M., Varutbangkul, V., Bahreini, R., Chung, S. H., Nenes, A., He, J., Yoo, K. Y., Beauchamp, J. L., Hodyss, R. P., Flagan, R. C., and Seinfeld, J. H.: particle Phase Acidity and Oligomer Formation in Secondary Organic Aerosol, Environ. Sci. Technol., 38, 6582-6589, 2004.

Gelencser, A. and Varga, Z.: Evaluation of the atmospheric significance of multiphase reactions in atmospheric secondary organic aerosol formation, Atmos. Chem. Phys., 5, 2823-2831, 2005.

Guazzotti, S. A., Suess, D. T., Coffee, K. R., Quinn, P. K., Bates, T. S., Wisthaler, A., Hansel, A., Ball, W. P., Dickerson, R.R., Neususs, C., Crutzen, P. J., and Prather, K. A.: Characterization of carbonaceous aerosols outflow from India and Arabia: Biomass/biofuel burning and fossil fuel combustion, J. Geophys. Res., 108, 4485, doi:10.1029/2002JD003277, 2003.

Hildemann, L. M., Mazurek, M. A., Cass, G. R., and Simoneit, B. R. T.: Quantitative characterization of urban sources of organic aerosol by high-resolution gas chromatography, Environ. Sci. Technol., 25, 1311-1325, 1991.

Hoffer, A., Gelencsér, A., Guyon, P., Kiss, G., Schmid, O., Frank, G., Artaxo, P., and Andreae, M. O.: Optical properties of humiclike substances (HULIS) in biomass-burning aerosols, Atmos. Chem. Phys. Discuss., 5, 7341-7360, 2005.

Husar, R. B. and Shu, W. R.: Thermal analysis of the Los Angeles smog aerosol, J. Appl. Meteorol., 14, 1558-1565, 1975.

Intergovernmental Panel on Climate Change (IPCC): Climate Change: The Scientific Basis, Cambridge University Press, UK, 2001.

Jacobson, M. Z.: Strong radiative heating due to the mixing state of black carbon in atmospheric aerosols, Nature, 409, 695-697, 2001.

Johnson, D., Utembe, S. R., Jenkin, M. E., Derwent, R. G., Hayman, G. D., Alfarra, M. R., Coe, H., and McFiggans, G.: Simulating regional scale secondary organic aerosol formation during the TORCH 2003 campaign in the southern UK, Atmos. Chem. Phys., 6, 403-418, 2006a.

Johnson, D., Utembe, S. R., and Jenkin, M. E.: Simulating the detailed chemical composition of secondary organic aerosol formed on a regional scale during the TORCH 2003 campaign in the southern UK, Atmos. Chem. Phys., 6, 419-431, 2006 b.

Kärcher, B. and Koop, T.: The role of organic aerosols in homogeneous ice formation, Atmos. Chem. Phys., 5, 703-714, 2005.

Kalberer, M., Paulsen, D., Sax, M. Steinbacher, M., Dommen, J., Prevot, A. S. H, Fisseha, R., Weingartner, E., Frankevich, V., Zenobi, R., and Baltensperger, U.: Identification of polymers as major components of atmospheric organic aerosols, Science, 
303, 1659-1662, 2004.

Kanakidou, M., Seinfeld, J. H., Pandis, S. N., Barnes, I., Dentener, F. J., Facchini, M. C., van Dingenen, R., Ervens, B., Nenes, A., Nielsen, C. J., Swietlicki, E., Putaud, J. P., Balkanski, Y., Fuzzi, S., Horth, J., Moortgat, G. K., Winterhalter, R., Myhre, C. E. L., Tsigaridis, K., Vignati, E., Stephanou, E. G., Wilson, J.: Organic aerosol and global climate modelling: A review, Atmos. Chem. Phys., 5, 1053-1123, 2005.

Kirchstetter, T. W., Novakov, T., Hobbs, P. V., and Magi, B.: Airborne measurements of carbonaceous aerosols in southern Africa during the dry, biomass burning season, J. Geophys. Res., 108, 8476, doi:10.1029/2002JD002171, 2003.

Kirchstetter, T. W., Novakov, T., and Hobbs, P. V.: Evidence that the spectral dependence of light absorption by aerosols is affected by organic carbon, J. Geophys. Res., 109, D21208, doi:10.1029/2004JD0004999, 2004.

Köhler, H.: The nucleus in the growth of hygroscopic droplets, Trans. Faraday Soc., 32, 1152-1161, 1936.

Kulmala, M.: How particles nucleate and grow, Science, 302, 10001001, 2003.

Kulmala, M., Vehkamäki, H., Petäjä, T., Dal Maso, M., Lauri, A., Kerminen V.-M., Birmili, W., and McMurry, P. H.: Formation and growth rates of ultrafine atmospheric particles: a review of observations, J. Aerosol Sci., 35, 143-176, 2004.

Kulmala, M., Petaja, T., Monkkonen, P., Koponen, I. K., Dal Maso, M., Aalto, P. P., Lehtinen, K. E. J., and Kerminen, V. M.: On the growth of nucleation mode particles: source rates of condensable vapor in polluted and clean environments, Atmos. Chem. Phys., 5, 409-416, 2005.

Leck, C. and Bigg, E. K.: Biogenic particles in the surface microlayer and overlaying atmosphere in the central Arctic Ocean during summer, Tellus, 57B, 305-316, 2005.

Lohmann, U. and Feichter, J.: Global indirect aerosol effects: a review, Atmos. Chem. Phys., 5, 715-737, 2005.

Lohmann, U. and Leck, C.: Importance of submicron surface active organic aerosols for pristine Arctic clouds, Tellus, 57B, 261-268, 2005.

Marcolli, C., Luo, B., and Peter, T.: Mixing of the organic aerosol fractions: liquids as the thermodynamically stable phases, J. Phys. Chem. A, 108, 2216-2224, 2004.

Marcolli, C., Luo, B. P., Peter, T., and Wienhold, F. G.: Internal mixing of the organic aerosol by gas phase diffusion of semivolatile organic compounds, Atmos. Chem. Phys., 4, 2593 2599, 2004.

Marcolli, C. and Peter, T.: Water activity in polyol/water systems: new UNIFAC parameterization, Atmos. Chem. Phys., 5, 15451555, 2005.

Maria, S. F., Russell, L. M., Turpin, B. J., Campos, T. L., Weber, R. J., and Huebert, B. J.: Source signatures of carbon monoxide and organic functional groups in Asian Pacific Regional Aerosol Characterization Experiment (ACE-Asia) submicron aerosol types, J. Geophys. Res., 108, 4022, doi:10.1029/2003D003703, 2003.

Martian-Reviejo, M. and Wirtz, K.: Is Benzene a Precursor for Secondary Organic Aerosol? Environ. Sci. Technol., 39, 1045-1054, 2005.

Mayol-Bracero, O. L., Guyon, P., Graham, B., Roberts, G., Andreae, M. O., Decesari, S., Facchini, M. C., Fuzzi, S., and Artaxo, P.: Water-soluble organic compounds in biomass burning aerosols over Amazonia: 2. Apportionment of the chemical composition and importance of the polyacidic fraction, J. Geophys. Res., 107, 8091, doi:10.1029/2001JD000522, 2002.

Mikhailov, E., Vlasenko, S., Niessner, R., and Pöschl, U.: Interaction of aerosol particles composed of protein and salts with water vapor: hygroscopic growth and microstructural rearrangement, Atmos. Chem. Phys., 4, 323-350, 2004.

Mircea, M., Facchini, M. C., Decesari, S., Cavalli, F., Emblico, L., Fuzzi, S., Vestin, A., Rissler, J., Swietlicki, E., Frank, G., Andreae, M. O., Maenhaut, W., Rudich, Y., and Artaxo, P.: Importance of the organic aerosol fraction for modeling aerosol hygroscopic growth and activation: a case study in the Amazon Basin, Atmos. Chem. Phys., 5, 3111-3126, 2005.

Mochida, M., Umemoto, N., Kawamura, K., and Uematsu, M.: Biomodal size distribution of C2-C4 dicarboxylic acids in the marine aerosols, Geophys. Res. Lett., 30, 1672, doi:10.129/2003GL017451, 2003

Molina, M. J., Ivanov, A. V., Trakhtenberg, S., and Molina, L. T.: Atmospheric evolution of organic aerosol, Geophys. Res. Lett. 31, L22104, doi:10.1029/2004GL020910, 2004.

Monn, C.: Exposure assessment of air pollutants: a review on spatial heterogeneity and indoor/outdoor/personal exposure to suspended particulate matter, nitrogen dioxide and ozone, Atmos. Environ., 35, 1-32, 2001.

Morrical, B. D., Fergenson D. P., and Prather, K. A.: Coupling twostep laser desorption/ionization with aerosol time-of-flight mass spectrometry for the analysis of individual organic particles, J. Am. Soc. Mass Spectrom., 9, 1068-1073, 1998.

Myhre, C. E. L. and Nielsen, C. J.: Optical properties in the UV and visible spectral region of organic acids relevant to tropospheric aerosols, Atmos. Chem. Phys., 4, 1759-1769, 2004.

Nenes, A., Charlson, R., Facchini, M. C., Kulmala, M., Laaksonen, A., and Seinfeld, J. H.: Can chemical effects on cloud droplet number rival the first indirect efffect?, Geophys. Res. Lett., 29, 1848, doi:10.1029/2002GL015295, 2002.

Novakov, T., Menon, S., Kirchstetter, T. W., Koch, D., and Hansen, J. E.: Aerosol organic carbon to black carbon ratios: Analysis of published data and implications for climate forcing, J. Geophys. Res., 110, D21205, doi:10.1029/2005JD005977, 2005.

O’Dowd, C. D., Facchini, M. C., Cavalli, F., Ceburnis, D., Mircea, M., Decesari, S., Fuzzi, S., Yoon, Y. J., and Putaud, J.-P.: Biogenically driven organic contribution to marine aerosol, Nature, 431, 676-680, 2004.

Odum, J. R., Hoffmann, T., Bowman, F., Collins, D., Flagan, R. C., and Seinfeld, J. H.: Gas/Particle partitioning and secondary organic aerosol yields, Environ. Sci. Technol., 30, 2580-2585, 1996.

Pöschl, U.: Formation and decomposition of hazardous chemical components contained in atmospheric aerosol particles, J. Aerosol Med., 15, 203-212, 2002.

Pöschl, U.: Atmospheric aerosols: composition, transformation, climate and health effects, Angew. Chem. Int. Ed., 44, 7520 7540, 2005.

Pöschl, U., Rudich, Y., and Ammann, M.: Kinetic model framework for aerosol and cloud surface chemistry and gas-particle interactions: Part 1 - general equations, parameters, and terminology, Atmos. Chem. Phys. Discuss., 5, 2111-2191, 2005.

Pun, B. K., Wu, S. Y., Seigneur, C., Seinfeld, J. H., Griffin, R. J., and Pandis, S. N.: Uncertainties in modelling sec- 
ondary organic aerosols: Three-dimensional modelling studies in Nashville/West Tennessee, Environ. Sci. Technol., 37, 36473661, 2003.

Randles, C. A., Russell, L. M., and Ramaswamy, V.: Hygroscopic and optical properties of organic sea salt aerosol and consequences for climate forcing, Geophys. Res. Lett., 31, L16108, doi:10.1029/2004GL020628, 2004.

Raymond, T. M. and Pandis, S. N.: Cloud activation of singlecomponent organic aerosol particles, J. Geophys. Res., 107, 4787, doi:10.1029/2002JD002159, 2002.

Rissler, J., Vestin, A., Swietlicki, E., Fisch, G., Zhou, J., Artaxo, P., and Andreae, M. O.: Size distribution and hygroscopic properties of aerosol particles from dry-season biomass burning in Amazonia, Atmos. Chem. Phys., 6, 471-491, 2006.

Russell, L. M., Maria, S. F., Myneni, S. C. B.: Mapping organic coatings on atmospheric particles, Geophys. Res. Lett., 29, 1779, doi:10.1029/2002GL014874, 2002.

Saxena, P. and Hildemann, L. M.: Water-soluble organics in atmospheric particles: A critical review of the literature and apliation of thermodynamics to identify candidate compounds, J. Atmos. Chem., 24, 47-109, 1996.

Schauer, C., Niessner, R., and Pöschl, U.: Polycyclic aromatic hydrocarbons in urban air particulate matter: decadal and seasonal trends, chemical degradation, and sampling artifacts, Environ. Sci. Technol., 37, 2861-2868, 2003.

Schauer, C., Niessner, R., and Pöschl, U.: Analysis of nitrated polycyclic aromatic hydrocarbons by liquid chromatography with fluorescence and mass spectrometry detection: air particulate matter, soot, and reaction product studies, Anal. Bioanal. Chem., 378, 725-736, 2004.

Svenningsson, B., Rissler, J., Swietlicki, E., Mircea, M., Bilde, M., Facchini, M. C., Decesari, S., Fuzzi, S., Zhou, J., Mønster, J., and Rosenørn, T.: Hygroscopic growth and critical supersaturations for mixed aerosol particles of inorganic and organic compounds of atmospheric relevance, Atmos. Chem. Phys., 6, 1937-1952, 2006.
Szidat, S., Jenk, T., Gaggeler, H., Synal, H., Fisseha, R., Baltensperger, U., Kalberer, M., Samburova, V., Wacker, L., Saurer, M., Schwikowski, M., and Hajdas, I.: Source apportionment of aerosols, what can be learnt from ${ }^{14} \mathrm{C}$ measurements in different carbonaceous particle fractions?, Radiocarbon, 46, 475-484, 2004.

Tervahattu, H., Juhanoja, J., and Kupiainen, K.: Identificaion of an organic coating on marine aerosol particles by TOF-SIMS, J. Geophys. Res., 107, 4319, doi:10.1029/2001JD001403, 2002.

Tolocka, M. P., Jang, M., Ginter, J., Cox, F., Kamens, R., and Johnston, M.: Formation of oligomers in secondary organic aerosol, Environ. Sci. Technol., 38, 1428-1434, 2004.

Topping, D. O., McFiggans, G. B., and Coe, H.: A curved multicomponent aerosol hygroscopicity model framework: Part 2 Including organic compounds, Atmos. Chem. Phys., 5, 1223$1242,2005$.

Tsigaridis, K. and Kanakidou, M.: Global modelling of secondary organic aerosol in the troposphere: A sensitivity analysis, Atmos. Chem. Phys., 3, 2879-2929, 2003.

Tsigaridis, K., Lathière, J., Kanakidou, M., and Hauglustaine, D. A.: Naturally driven variability in the global secondary organic aerosol over a decade, Atmos. Chem. Phys., 5, 1891-1904, 2005

Turpin, B. J., Saxena, P., and Andrews, E.: Measuring and simulating particulate organics in the atmosphere: problems and prospects, Atmos. Environ., 34, 2983-3013, 2000.

Zhang, Q., Worsnop, D. R., Canagaratna, M. R., and Jimenez, J.-L.: Hydrocarbon-like and oxygenated organic aerosols in Pittsburgh: insights into sources and processes of organic aerosols, Atmos. Chem. Phys., 5, 3289-3311, 2005. 